\title{
CASES-99: A Comprehensive Investigation of the Stable Nocturnal Boundary Layer
}

\author{
by Gregory S. Poulos, William Blumen, David C. Fritts, Julie K. Lundquist, \\ Jielun Sun, Sean P. Burns, Carmen Nappo, Robert Banta, Rob Newsom, \\ Joan Cuxart, Enric Terradellas, Ben Balsley, and Michael Jensen
}

Contrary to its currently known characteristics, the nocturnal boundary layer over the Great Plains is frequently populated with a variety of turbulence-producing phenomena.

C ASES-99 considers four scientific questions primarily related to the stable, nocturnal boundary layer, including the transition periods. The CASES-99 field program attempted to identify the sources and to quantify the physical characteristics of atmospheric phenomena occurring from the formative stages of the $\mathrm{NBL}^{1}$ until its eventual breakup during the morning transition. The follow-up pro-

${ }^{1}$ Acronyms not defined in the text are defined in the appendix.

AFFILIATIONS: Poulos AND FrITTS—Colorado Research Associates/ NWRA, Boulder, Colorado; BLUMEN AND LUNDQUIST—Program in Atmospheric and Oceanic Sciences, University of Colorado, Boulder, Colorado; Sun AND BuRns-National Center for Atmospheric Research, Boulder, Colorado; NAPPO-NOAA Air Resources Laboratory, ATDD, Oak Ridge, Tennessee; BANTA-NOAA Environmental Technology Laboratory, Boulder, Colorado; NEWSOM-Cooperative Institute for Research in the Atmosphere, Colorado State University, Fort Collins, Colorado; CUXART AND Terradellas - Instituto National de Meteorologia, Barcelona, Spain; BALSLEY AND JENSEN-Cooperative Institute for Research in Environmental Sciences, University of Colorado, Boulder, Colorado CORRESPONDING AUTHOR: Gregory S. Poulos, Colorado Research Associates/NWRA, 3380 Mitchell Lane, Boulder, CO 80301

E-mail: gsp@co-ra.com

In final form 18 December 200 I

(C) 2002 American Meteorological Society gram of data analyses, theoretical study, and numerical simulations is focusing on investigations of the CASES-99 scientific goals, which are as follows.

1) To provide a time history of internal gravity waves, Kelvin-Helmholtz shear instabilities, and turbulence events in the nighttime stable boundary layer, and to evaluate the relative contributions to intermittent heat, moisture, and momentum fluxes that can be associated with the sources of these phenomena. Sources of turbulence outbursts include, but are not restricted to, surface and elevated shear layers and Kelvin-Helmholtz instability, internal gravity waves within the stable boundary layer, drainage current fronts, and surface vortex shedding.

2) To measure heat and momentum fluxes and their divergences accompanying the events contributing to turbulence, transports, and mixing throughout the nocturnal boundary layer, and especially within the surface layer $(\sim 10-20 \mathrm{~m})$, and to assess the departures from similarity theory under weakly stable and very stable conditions.

3) To define the relative importance of surface heterogeneity, particularly under very stable light wind conditions, on the initiation of shallow drainage currents (few tens of meters in depth) and the horizontal and vertical transports that accompany such boundary undulations. 
4) To acquire data during the transition from a convective to stable boundary layer regime and vice versa to compare with existing models of this transition, and to assess the role of this transition period in the initiation of inertial oscillations and the enhancement of low-level jets approximately 100 $300 \mathrm{~m}$ above the surface.

In October 1999, largely due to the grassroots, cooperative efforts of many scientists, a massive deployment of a variety of instruments took a series of observations of the generally stable nocturnal atmosphere over southeastern Kansas. As a result of that effort, the four scientific goals of the project appear to be not only achievable, but knowledge of those areas can be advanced significantly. In addition, this large dataset represents a significant opportunity for progress toward scientific goals of other researchers interested in the PBL who did not actively participate in the CASES-99 field program. Although the widest variety of instrument platforms were utilized during the overnight IOPs, in fact, the majority of instruments operated throughout the diurnal cycle, including a number of instruments with high-frequency $(>1 \mathrm{~Hz})$ observations.

CASES-99 occurred within the umbrella of the more general goals of the CASES concept, which were to provide a long-term facility for scientists to study the mesoscale processes of meteorology, hydrology, climate, chemistry, ecology, and their complex linkages, and to serve as a focal point to provide field experience for students of the natural sciences. The Walnut River watershed in southeastern Kansas (see Figs. 1 and 2) was chosen by scientists from these many disciplines as an ideal location for the study of these exchanges. The WRW is a hydrologically confined region of relatively flat terrain, varied ecosystem characteristics, and limited quantifiable external sources of chemical constituents (see Fig. 2). From the perspective of the atmospheric scientist, the fact that the WRW is nested within the ARM-CART site and the ABLE from which climatological norms can be established, is a significant benefit. ABLE instrumentation sites are partially shown in Fig. 2. The first CASES field program was CASES-97, which had a variety of goals within the disciplines of meteorology, ecology, chemistry, and hydrology (LeMone et al. 2000). The CASES-99 field experiment was considerably smaller in geographic extent and focused on exchanges in the soil-biosphere-atmosphere interface, specifically those during stable atmospheric conditions.

Participants. The program was fortunate to have participants from a broad spectrum of institutions and

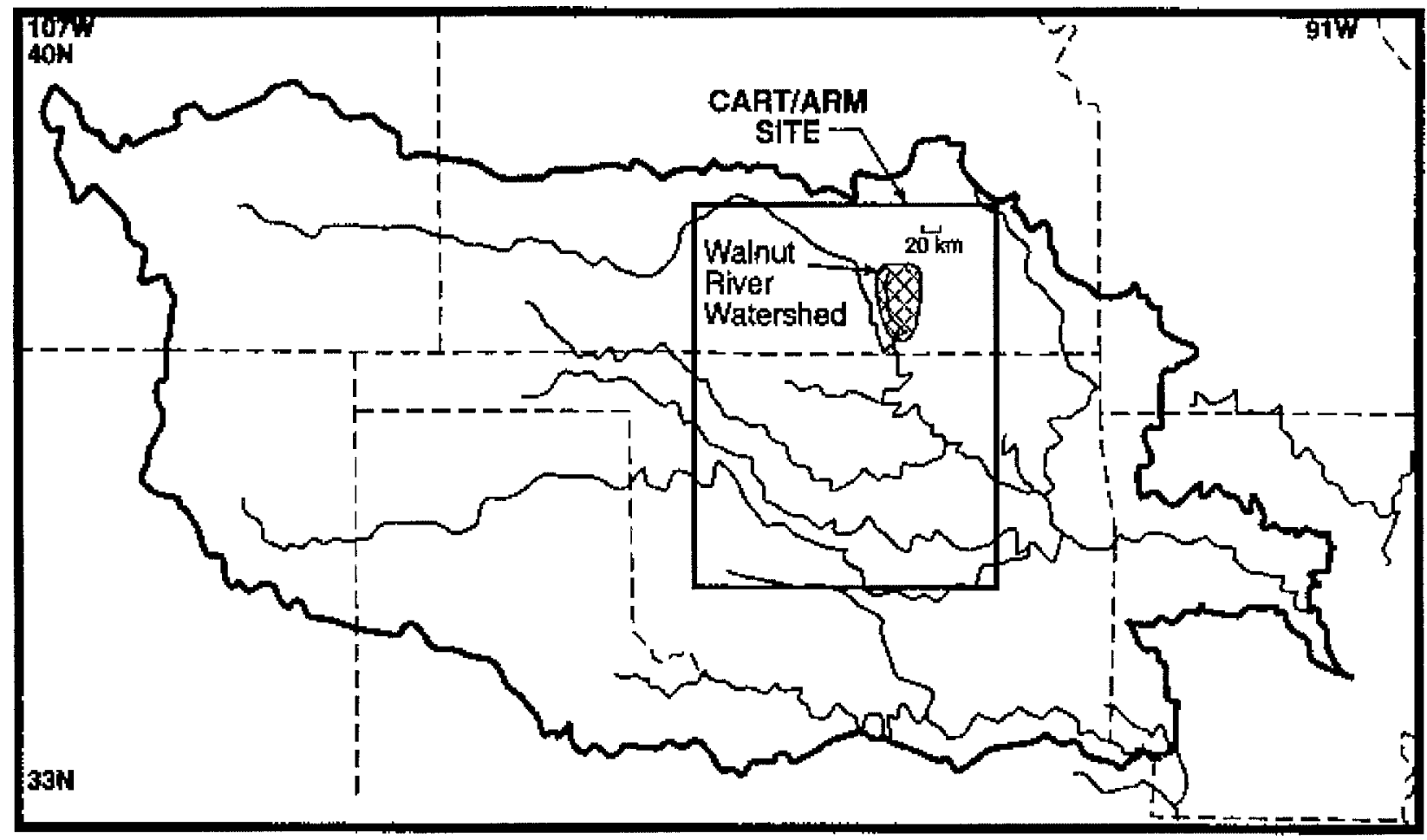

FIG. I. The Arkansas River Watershed and subdomain of the ARM-CART site within which the CASES-99 Field Experiment was held. Note that the WRW represents a minor basin within the larger watershed. 
geographic locations (see Table 1). By cooperatively organizing the experiment from the early stages, participants were able to leverage their instrumentation into a considerably more complete, unique, field experiment than they could field themselves. For CASES-99, this structure thus far has resulted in strongly collaborative research efforts, a comprehensive consideration of viewpoints when setting mutually beneficial scientific goals and experimental design, and a broad approach to the solution to the various questions under investigation.

Background. CASES-99 is motivated by the generally large number of outstanding questions regarding atmospheric behavior in the NBL, and particularly the stable NBL (Nappo and Johansson 1998). There have been several practical reasons why this is so: 1) the logistics of field work during nighttime hours are somewhat more difficult than during the daytime; 2 ) the magnitude of turbulence during the nighttime is generally less than that during the daytime-in midlatitudes, particularly under clear skies-such that this period is considered relatively quiescent; 3 ) the generally stable conditions during the clear-sky NBL make the characterization of fluxes difficult; and 4) the period of observations does not coincide with the typical human wake cycle.

Regardless of these factors, utilizing some traditional, nontraditional, and experimental instrumentation, during CASES-99 we found that the NBL can be sampled sufficiently to achieve our scientific goals, as outlined in our preliminary analysis. A large part of the motivation for CASES-99 was the need to resolve problems encountered by numerical models attempting to capture atmospheric phenomena on scales from a few meters to a few hundreds of kilometers during stably stratified nocturnal conditions (Gryning 1985; McNider et al. 1995; Poulos and
$50 \mathrm{~km}$

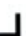

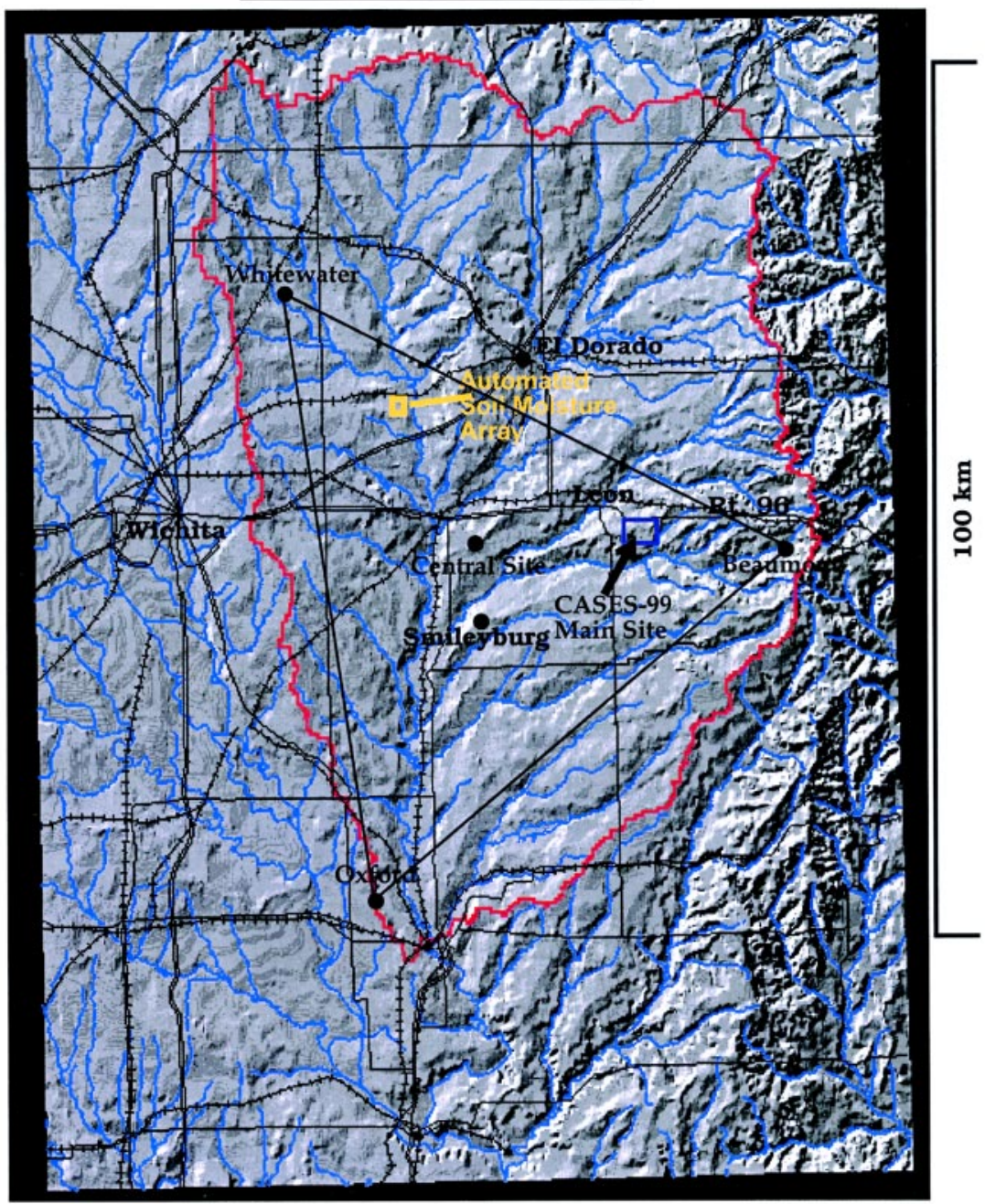

FIG. 2. The WRW and site of CASES-99 field program. The CASES-99 main site is outlined in the small rectangle just to the right of the ABLE central site, southeast of Leon, KS (see Fig. 3 for details). The filled circles indiate areas of existing, meso- $\beta$-scale instrumentation of ABLE (towers, sodars, wind profilers). Note the soil properties measurement site to the southeast of Whitewater.

Bossert 1995). Our modeling approach both during and after the field experiment, is described. Most numerical models on these scales in the surface layer depend-inasmuch as the surface layer is defined for the NBL-on similarity theory-based parameterizations (e.g., Louis 1979 and variations), although a variety of approaches have been attempted (Hartel and Kleiser 1998). As discussed by Mahrt (1998, 1999), however, stably stratified atmospheric surface fluxes are not adequately described by existing MoninObukhov similarity theory, which is more appropriately applied to the weakly stable, neutral, and convective boundary layers (Derbyshire 1995; Hill 1997). Still, this theory is effectively applied in modern numerical weather prediction models (Chen et al. 1997). 
TABLE I. An alphabetical list of participants in the CASES-99 field experiment. Note that, for brevity, in some cases only one representative from an institution is listed although more than one representative participated.

\begin{tabular}{|c|c|}
\hline Name & Affiliation \\
\hline Ben Balsley & University of Colorado \\
\hline Bob Banta & NOAA/ETL \\
\hline Bill Blumen & University of Colorado \\
\hline Sean Burns & NCAR \\
\hline Mark Coleman & Army Research Laboratory \\
\hline Dan Cooper & LANL \\
\hline Rich Coulter & Argonne National Laboratory \\
\hline Joan Cuxart & Instituto Nacional de Meteorologia \\
\hline Henk deBruin & Wageningen Agricultural University, Netherlands \\
\hline Chris Doran & Pacific Northwest Laboratory \\
\hline Richard Eckmann & INEL \\
\hline William Eichinger & University of lowa \\
\hline Steve Frasier & University of Massachusetts, Amherst \\
\hline Dave Fritts & CoRA \\
\hline Oscar Hartogensis & Wageningen Agricultural University, Netherlands \\
\hline Mark Hoder & University of Wyoming \\
\hline Mike Jensen & University of Colorado \\
\hline Jerry Klazura & ANL (onsite) \\
\hline Julie Lundquist & University of Colorado \\
\hline Larry Mahrt & Oregon State University \\
\hline Dave Miller & University of Connecticut \\
\hline Carmen Nappo & Oak Ridge/NOAA/ATDD \\
\hline Rob Newsom & NOAA/ETL \\
\hline Steve Oncley & NCAR \\
\hline Greg Poulos & CoRA \\
\hline John Prueger & National Soil Tilth Laboratory \\
\hline Russ Qualls & University of Colorado \\
\hline Maria Rosa Soler & University of Barcelona \\
\hline Greg Stossmeister & UCAR JOSS \\
\hline Jielun Sun & NCAR \\
\hline Marv Wesely & Argonne National Laboratory \\
\hline
\end{tabular}

Ridge, Tennessee, during 1987-88 (Nappo 1991) and in the CASES Walnut River watershed field site during March 1995 (Mahrt 1999; Mahrt et al. 1997) indicate that a significant fraction of the nighttime vertical fluxes of heat, moisture, and momentum occur during such intermittent bursts (Howell and Sun 1997). Other measurements have shown that intermittent bursts of turbulence and mixing can also occur multiple times on a given night (Weber and Kurzeja 1991). Such behavior is verified by the detailed measurements taken during CASES-99, on the majority of IOPs. One-dimensional modeling of this intermittent behavior in the nighttime boundary layer has been reported by Revelle (1993), but the underlying turbulent transfer mechanisms are not yet clearly understood. Quantitative formulations of NBL and surface layer fluxes requires a detailed understanding of the processes responsible for the turbulent burst activity, which we believe will be partly achieved by the scientific community with CASES-99 observations. Furthermore, recent advances in direct numerical simulation techniques have begun to show promise in the study of this problem with solutions for Re $>10000$ (Werne and Fritts 1999).

The nonstationarity associated with shear flow instabilities, overturning Kelvin-Helmholtz billows, terrain-generated phenomena, surface heterogeneity, and heat and

Formulating surface fluxes in stably stratified conditions is made difficult by a number of factors. First, the NBL, as verified in the CASES-99 data analysis shown below, is often characterized by intermittent turbulent bursts that may last from tens of seconds to minutes. These sporadic or episodic events that populate the nighttime stable boundary layer (Nappo 1991; Blumen et al. 2001) do not lead to statistically steadystate turbulence, which underlies one of the major assumptions of existing theory. Data taken, for example, in the Walker Branch watershed near Oak radiative flux divergences contributes to the uncertainties and conceptual difficulties encountered in the various attempts to construct a physical basis for events and concomitant vertical transports that occur under statically stable regimes (Caughey and Readings 1975; Finnigan et al. 1984; Lenschow et al. 1998a,b; Horst and Doran 1986; Howell and Mahrt 1997). Most studies to date have not been able to establish the source(s) of intermittent turbulence that is often observed at ground level. This lack of knowledge inhibits the development of reliable parameter- 
izations of the very dynamically and statically stable nighttime boundary layer. Several efforts, for example, have attempted to identify the source(s) of errors in surface layer parameterizations for stable flows (Poulos 1996; Mahrt 1998). It is argued by Poulos (1996) that an oscillation created in the stable surface layer parameterization can induce occasionally unrealistic cooling under low wind conditions. The resulting gradient is influenced by the turbulence parameterization and, in some cases, "runaway" cooling can occur. This undesirable effect is also discussed by Mahrt (1998) to be the result of radiatively driven heat loss that is not sufficiently compensated for by the heat flux calculated in the stable surface layer parameterization. This aspect is further complicated by the important influence of soil moisture, which was observed during CASES-99, on NBL evolution, a variable that is generally poorly initialized in numerical models (Banta and Gannon 1995). In many cases, the parameterized surface layer fluxes are inadequately addressed by the turbulent diffusion parameterization that is responsible for diffusing strong radiative cooling to greater heights. Derbyshire (1999) has recently examined this problem by a combined numerical and theoretical study. He refers to this modeling deficiency as a "physical boundary instability." To improve these parameterizations a more accurate physical basis must be found for the clear-sky NBL case that often leads to dynamically stable conditions ( $\mathrm{Ri}>$ $0.25)$.

FIELD EXPERIMENT DESCRIPTION. The CASES-99 field experiment was held during the month of October 1999 in southeast Kansas (Fig. 1). This period was chosen, based on data archived by the Wichita National Weather Service, for its climatologically high frequency of clear, calm nights and therefore increased likelihood of stable boundary layer development. Further, a review of measurements from ABLE for October 1997 showed that approximately $40 \%$ of the nights had mostly clear skies and light near-surface winds. The remainder of the nights had partial or complete cloud cover, altering the radiative balance significantly, and would be appropriate for study of the NBL under cloudy conditions. Given this information the research group believed that 4-6 IOPs would be logistically possible during October 1999. In fact, 11 IOPs were completed.

To measure the atmosphere sufficiently to achieve the science goals, in situ boundary/surface layer instrumentation provided jointly by the CASES-99 investigators, NCAR ATD, ARM, and ABLE (see Table 1 and Figs. 2-4), were deployed with specific vertical and horizontal sampling strategies. In the horizontal, many of the instruments were focused on defining the meso- $\gamma$ scale $(2-20 \mathrm{~km})$ and smaller NBL evolution of temperature, moisture, wind, soil temperature, soil moisture, constituent profiles, and the wave and turbulence fluxes of heat and momentum. Existing data sources in and around the Walnut River watershed field site, such as from the ongoing ABLE (see Fig. 2), the National Weather Service in Wichita, and the ARM-CART site (Fig. 1), provided enhanced observation of mesoscale features of the meso- $\beta$ scale ( $20-200 \mathrm{~km})$. Soil properties, including moisture, were intensively studied at a site to the southeast of Whitewater. The assimilation of both standard and state-of-the-art instrumentation provided the opportunity to construct the most comprehensive observational depiction of the structure, evolution, and instability of the NBL in this region to date.

Experimental design. CASES-99 field observations were organized by the horizontal and vertical scales of interest. In the horizontal plane, relatively scarce information is available to describe the extent of intermittent flux sources and stable NBL heterogeneity. Whereas in the convective boundary layer it is well known that regularly overturning eddies are largely responsible for the fluxes and that these eddies have a certain size determined partly by CBL depth, such statements cannot be made with certainty in the stable NBL. In fact, little is known about the horizontal variability of NBL characteristics, which is a significant factor when attempting to understand the significance of intermittent NBL turbulence events, regardless of source.

HORIZONTAL INFORMATION. In the horizontal plane, the vertices of a concentric set of triangles determined the instrument locations (Figs. 2 and 3). The outermost triangle (not shown) was a part of the existing ARM-CART instrument array in the KansasOklahoma region, and surrounded the CASES-99 main site on at scale of $\sim 150 \mathrm{~km}$. ARM-CART participated only during IOPs with enhanced rawinsondes and wind profiler observations for CASES-99 use. Also at the meso- $\beta$ scale, the preexisting and slightly enhanced ABLE instrumentation was utilized at the vertices of a triangle of approximately $60 \mathrm{~km}$ on a side (see Fig. 2). The ABLE wind profilers were temporarily modified to provide half-hourly interval winds and RASS data were also available. ABLE also provided convenient, continuous, online data access, additional surface stations within the Walnut River 
Beaumont $16 \mathrm{~km} \longrightarrow$

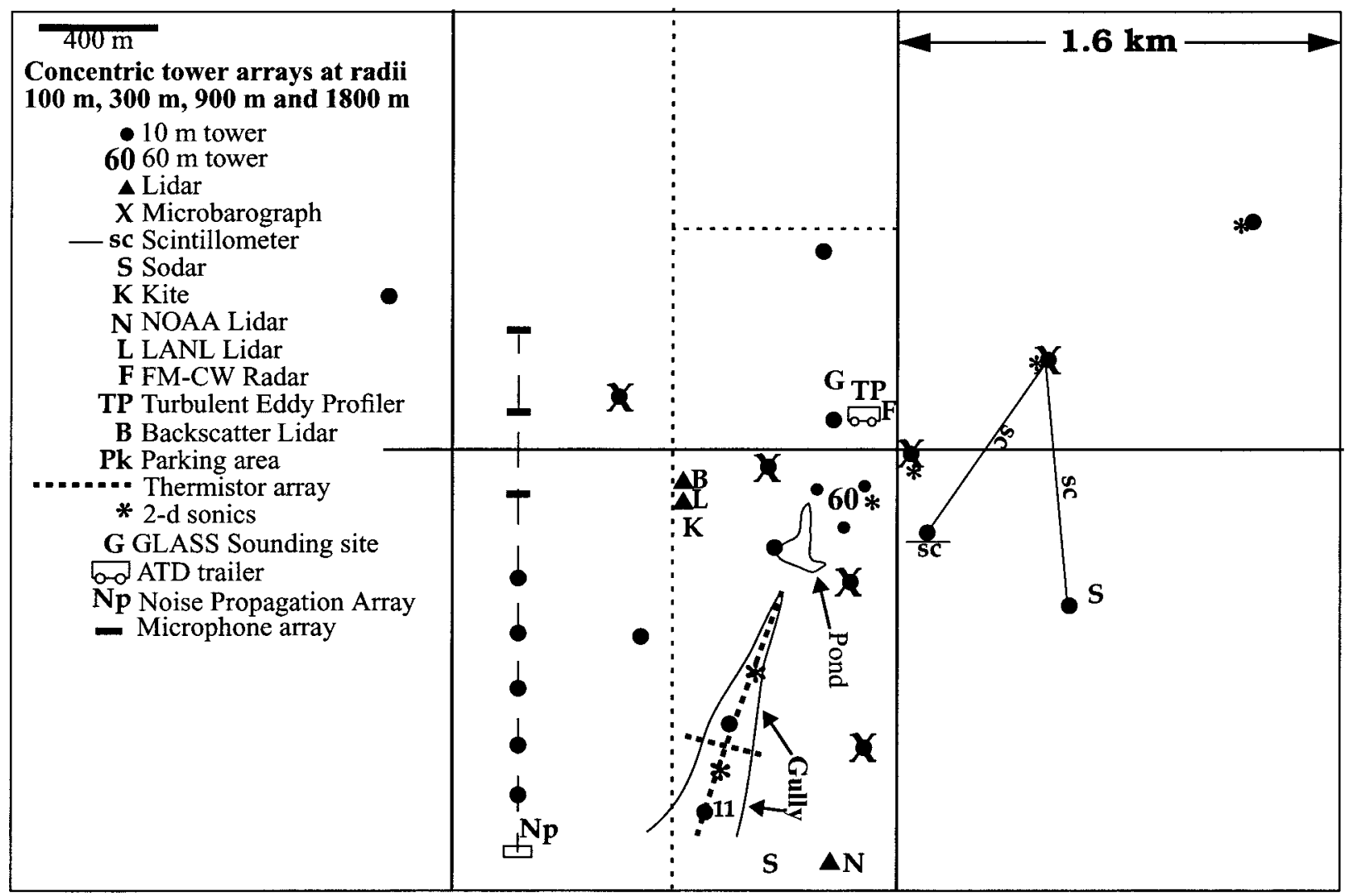

FIG. 3. The CASES-99 main site $(4.8 \mathrm{~km}$ by $3.2 \mathrm{~km})$. The $60-\mathrm{m}$ tower is the center of a series of concentric triangles at whose vertices a variety of instruments, among others, are placed. The gully study areas lies southwest of the 60-m tower.

watershed, and the infrastructure for the CASES-99 operations trailer at the Argonne Project Office, not far from the CASES-99 main site. The next roughly concentric triangle that defined instrument locations was on the scale of $\sim 15 \mathrm{~km}$, and was supplied by NCAR's ATD via Integrated Sounding Sites (ISS; not shown). Each ISS consisted of a surface station with a GPS rawinsonde and continuous monitoring by a wind profiler. These larger-scale triangles, relative to the scale of the CASES-99 main site, provide context and horizontal heterogeneity information during stable NBL conditions.

At the meso- $\gamma$ and microscale $(2-2000 \mathrm{~m}$ ), four additional concentric triangles define the CASES-99 main site (Fig. 3), all of which center upon the $60-\mathrm{m}$ tower. These triangles sequentially decrease in scale (as defined by the radii to the triangle vertices) as follows: $1800,900,300$, and $100 \mathrm{~m}$. The vertices of each triangle are instrumented with $10-$ or $20-\mathrm{Hz}$-recording thermosonic anemometers and other instrumentation depending on the supplier (typically standard meteorological instrumentation, and occasionally soil temperature and moisture systems). Thus, heretofore unprecedented information is available regarding the horizontal distribution of stable NBL characteristics, phenomena, and the associated fluxes. At the vertices of the innermost triangles (100 and $300 \mathrm{~m}$ ), microbarographs sampling at $1 \mathrm{~Hz}$ were installed to capture gravity wave phase speed, amplitude, and orientation, as well as the pressure fluctuations associated with various NBL phenomena (e.g., DenholmPrice and Rees 1999).

Important information on the horizontal scale of NBL phenomena is also obtained from a variety of other instruments in the CASES-99 main site, including a scanning high-resolution Doppler lidar, a Raman lidar, multiple scintillometers with measurements horizontally averaged turbulence parameters (e.g., Kunkel and Walters 1982; $C_{T}^{2}$, but with differing path lengths), and to some extent the turbulent eddy profiler. Additionally, two aircraft, the NOAA Long-EZ and the Wyoming King Air, were available for IOP flights, occasionally flying twice per night. The aircraft were able to sample the wind compo- 
nents, $\left(\mathrm{H}_{2} \mathrm{O}, \mathrm{CO}_{2}\right.$, and temperature among others) at $25 \mathrm{~Hz}$ and provide valuable information linking the fixed-location instrument observations to the phenomena observed. During the late afternoon transition and morning transition, when some light remained, the Wyoming King Air was able to fly as low as $50 \mathrm{~m}$ AGL along certain flight paths, allowing for comparison with some instruments on the 60-m tower.

Data on small horizontal scales $[O(10) \mathrm{m}]$ were also provided by dedicated instrumentation arranged in a shallow gully to the south-southwest of the $60-\mathrm{m}$ tower. This gully (see Fig. 3 ) is $\sim 10 \mathrm{~m}$ deep but experienced regular katabatic flow as measured by a variety of instrumentation. The gully measurements are able to show how overlying turbulence in strongly radiative conditions can influence near-surface flows over land surfaces common worldwide. In the gully were two $10-\mathrm{m}$ towers instrumented with thermosonic anemometers and slow-response sensors, 18 thermocouples in the alongand cross-valley axis directions, and a number of $2 \mathrm{D}$ sonic anemometers placed in strategic locations. Despite strong gully stability, its katabatic flow was frequently influenced by flow above it, as is discussed below (preliminary results: IOP-7, 18 October 1999, intermittent phenomena).

VERTICAL INFORMATION. One of the most important aspects of quantifying the influence of various NBL phenomena on NBL evolution and the ambient atmosphere is observing the relevant atmospheric fields with height. Analysis of dynamic and static stability was considered a crucial part of the CASES-99 measurements. During CASES-99 a 60-m tower, a kite profiling system, vertically profiling lidars (the NOAA HRDL, the University of Iowa wind lidar and scanning aerosol lidar, and the LANL vertical profiling lidar), tethersondes, radars, and sodars were the primary instruments in use (see Figs. 3 and 4). Additionally, during IOPs frequent rawinsondes were released, most often at 1-h intervals but varying from half-hourly to bihourly during the overnight period. Unfortunately, wind data from the rawinsondes are unavailable below $\sim 150 \mathrm{~m}$ AGL during many flights.

Regarding vertical structure, the 60 -m tower provided by NCAR ATD (Fig. 4) acted as the centerpoint for the CASES-99 experiment, with an unusually large number of sensors with high sampling rates mounted upon it. At six levels, from 2.5 to $60 \mathrm{~m}, 10$ or $20-\mathrm{Hz}$ sonic anemometers or thermosonic anemometers were mounted in roughly $10-\mathrm{m}$ intervals (Fig. 4). Between those sensors slow-response sensors provided additional information at 5-m separation. Also, below $10 \mathrm{~m} \mathrm{AGL}$, hot-film sensors recorded winds at $200 \mathrm{~Hz}$. At 10, 20, and $40 \mathrm{~m}$, hot-wire anemometers gathered data for dissipation evaluation at $4.8 \mathrm{KHz}$. Additionally, microbarographs sampling to $1 \mathrm{~Pa}$ at $2 \mathrm{~Hz}$ were mounted at 1,30 , and $50 \mathrm{~m}$ with 
the intent of providing a unique observation of vertical propagation of coherent pressure disturbances.

Thirty-four thermocouples (E-type, chromel/constantan, $0.0254-\mathrm{mm}$ diameter) capable of $5-\mathrm{Hz}$ absolute temperature measurements were distributed in $1.8-\mathrm{m}$ increments from 2.3 to $58.1 \mathrm{~m} \mathrm{AGL}$, providing unprecedented vertical resolution of temperature changes induced by the various NBL phenomena sampled. The advantage of thermocouple temperature is its accuracy of the temperature difference between different vertical levels. The high accuracy of the thermocouple temperature is achieved by referencing thermocouples from different vertical levels to the same data logger where a common reference temperature is defined. The thermocouples deployed in CASES-99 are the same as the one discussed in Cheney and Businger (1990), with an estimated accuracy for $\Delta T$ of $0.01^{\circ} \mathrm{C}$. The absolute accuracy of the reference thermistor is $0.25^{\circ} \mathrm{C}$ for the range of $0^{\circ}-40^{\circ} \mathrm{C}$.

Comparisons during nighttime between aspirated and thermocouple temperatures indicate that the absolute temperature difference between the two types of temperature measurements is about $0.1^{\circ} \mathrm{C}$.
Comparing the three types of temperature measurements on the main tower, Fig. 5 indicates that the thermocouple temperature captures all similar highfrequency temperature fluctuations as the sonic anemometer does, which are missed by aspirated temperature sensor. In addition, it has the absolute accuracy of the slow-response aspirated temperature sensor, which the sonic anemometer lacks.

To study all the heating sources and sinks that affect the validity of Monin-Obukhov similarity theory, radiative flux divergence was carefully measured by 10 Eppley precision infrared radiometers positioned at 48 and $2 \mathrm{~m}$ AGL. The contribution of the vertical divergence has been measured in previous experiments (Funk 1960; Nkemdirim 1978; Gopalakdrishnan et al. 1998) but the interpretation of the results is controversial and not in agreement with theoretical studies (Rider and Robinson 1951; Elliott 1964). This is the first time that both the radiative flux divergence and the sensible heat flux divergence can be calculated using simultaneous observations. With the eight vertical levels of turbulent flux measurements, the total heat budget can be studied under stable nocturnal boundary layer conditions.

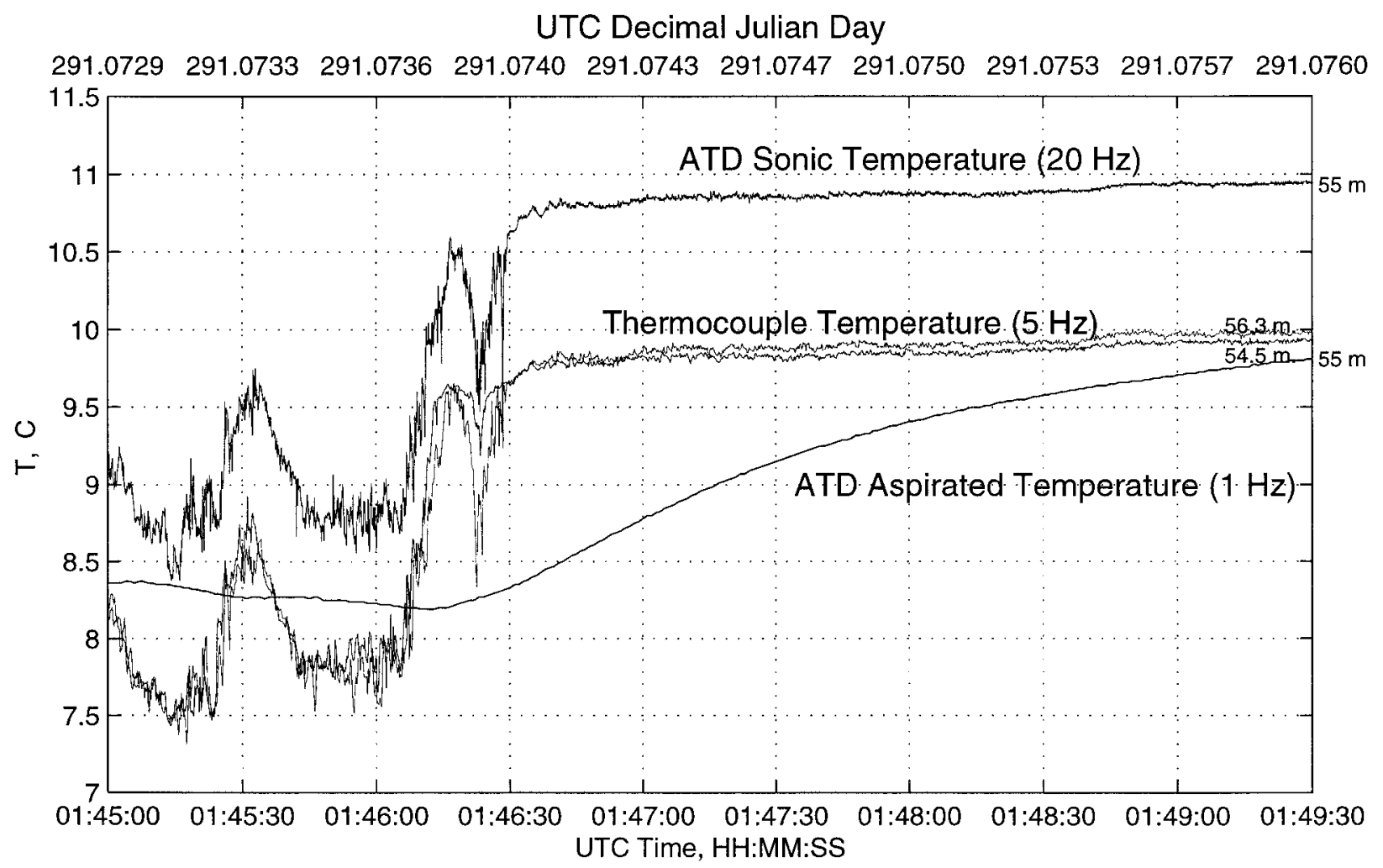

Fig. 5. A comparison of the temperature $\left({ }^{\circ} \mathrm{C}\right)$ from a $20-\mathrm{Hz}$ thermosonic anemometer, an aspirated temperature sensor, and a $5-\mathrm{Hz}$ thermocouple at $55 \mathrm{~m}$ on the $60-\mathrm{m}$ tower. 
Approximately $200 \mathrm{~m}$ to the northeast of the $60-\mathrm{m}$ tower a variety of instruments were placed that also sampled the atmosphere in the vertical (Fig. 3). The FM-CW radar continuously measured $C_{N}^{2}$ in this area, providing constant real-time evaluation of turbulent phenomena from $60 \mathrm{~m}$ to over $1 \mathrm{~km}$ at $2-\mathrm{m}$ vertical resolution. This information was of great use, along with the other instruments capable of real-time display such as the sodar, HRDL, and kite, in guiding airborne resources toward regions of significant instability. Also, in this area was the TEP, whose experimental capability to detect three-dimensional winds in an $\sim 25^{\circ}$ cone above it, may give some of the first information of this kind for intermittent NBL turbulence. Also, in this area was the GPS rawinsonde.

Other instruments also sampled the vertical structure of the NBL on the main site (Fig. 3). To the southeast of the 60-m tower, a sodar sampled the winds and turbulent quantities at $\sim 8$-m vertical resolution to $100 \mathrm{~m}$ AGL, frequently detecting shear instability and overturning. Also in this area was a tethersonde capable of high vertical resolution vertical profiles of mean atmospheric quantities during relatively quiescent periods $\left(U<7 \mathrm{~m} \mathrm{~s}^{-1}\right)$, where $U$ is the total horizontal wind speed. To the west of the $60-\mathrm{m}$ tower, a cluster of instruments, including two lidars and a vertically profiling kite (with a balloon for calm periods) added further information. The kite was able to frequently take vertical profiles and, with multiple highrate instruments hanging from its tether, sample elevated turbulent events with a high sampling rate for long periods. The Raman lidar provides high vertical resolution information $(\sim 4 \mathrm{~km})$ about specific humidity distribution, and, combined with a collocated scanning aerosol backscatter lidar, identify significant layers within the NBL, and possibly instabilities that are generated at those levels.

To the south, at approximately the same altitude as the base of the $60-\mathrm{m}$ tower, the HRDL lidar detected Doppler velocities in variety of flexible scanning strategies (Grund et al. 2001). When scanning repeatedly at one orientation (generally into the mean wind) over a variety of elevation angles, the HRDL was able to capture wave activity and shear layers not seen clearly by any other instrument. When staring vertically this instrument was able to capture the vertical velocity associated with horizontally propagating internal gravity waves. Other scanning strategies allowed the HRDL to capture variances of the horizontal components of velocity.

Intensive observational periods (IOPs). Table 2 lists the date, time, short events summary, and aircraft avail- ability for CASES-99 IOPs. During the month of October there were 12 designated IOPs (although number 11 was cancelled), far exceeding our expectations, and all of the resources were easily used. According to temperature data taken on the $60-\mathrm{m}$ tower, the temperature increase was $5.5^{\circ} \mathrm{C}\left(\right.$ or $\left.275^{\circ} \mathrm{C} \mathrm{km}^{-1}\right)$, on average from the surface to $20 \mathrm{~m} \mathrm{AGL}$, showing that CASES-99 sampled very statically stable conditions during IOPs. This unexpectedly large number of IOPs was due to an exceptionally dry October, particularly from 1 to 27 October. Indeed, there are a number of non-IOP nights that should contribute significantly to stable NBL research.

Throughout the field phase of CASES-99 it was recognized, via real-time instrumentation and daily IOP summaries from various investigators, that we were successfully capturing the events that would make our scientific goals achievable. Thus, we have attempted to compile tables of significant turbulence events and events where atmospheric change was significant, based on data obtained from instrumentation on the 60-m tower, the ABLE data array, and the Wyoming King Air. (Our event summary is not shown here but can be found online at www.cora.com/cases/CASES-99.html.) To briefly summarize the contents of those tables, we found the following number of different events from overnight periods during October 1999: 4 synoptic frontal passages, 10 density current passages (e.g., Blumen et al. 1999), 6 low-level and 3 upper-level (aircraft) episodic turbulence events, 7 miscellaneous events (such as unusually large-amplitude wave activity or short timescale temperature changes), inertial oscillations (Table 3), and 13 low-level jets observed in the height range 100 $<z<300 \mathrm{~m}$. These tables are likely to be incomplete for a number of reasons, including 1) not evaluating the entire CASES-99 dataset, 2) incomplete datasets, 3) location of the instruments chosen for review, and 4) the inadequacy of some instruments in detecting events. The tables have been compiled as a guide for investigators seeking particular, individual events, but the user should expect other events in addition to those listed, and, perhaps, a reinterpretation of a cited event.

Operational forecast guidance. During the CASES-99 field phase, operational forecast guidance was provided by the UCAR JOSS in cooperation with the Wichita NWS and numerical weather prediction using the RAMS being run on a Linux cluster at Colorado State University. The RAMS forecasts used $3.5-\mathrm{km}$ and $25-\mathrm{m}$ grid spacing in the horizontal and vertical, respectively. These mesh sizes are considered 
TABLE 2. IOP nights during CASES-99 field experiment. Column 4 contains the estimated maximum $T_{20 \mathrm{~m}}$ $-T_{0.5 \mathrm{~m}}$ and a conversion of that value to ${ }^{\circ} \mathrm{C} \mathrm{km}^{-1}$ in parentheses. The other columns are self-explanatory.

\begin{tabular}{|c|c|c|c|c|c|}
\hline $\begin{array}{l}\text { IOP } \\
\text { No. }\end{array}$ & $\begin{array}{l}\text { Start date: } \\
\text { time UTC }\end{array}$ & $\begin{array}{l}\text { End date: } \\
\text { time UTC }\end{array}$ & $\begin{array}{c}\text { Short description and max } \\
\Delta T_{20.0-0.5 \mathrm{~m}} \text { in }{ }^{\circ} \mathrm{C} \text { and equivalent } \\
\text { lapse rate }\left({ }^{\circ} \mathrm{C} \mathrm{km}^{-1}\right)\end{array}$ & $\begin{array}{l}\text { King Air } \\
\text { flight times } \\
\text { (UTC) }\end{array}$ & $\begin{array}{l}\text { Long EZ } \\
\text { flight times } \\
\text { (UTC) }\end{array}$ \\
\hline 1 & 4 Oct: 2200 & 5 Oct: 1100 & Clear skies, light winds. $\Delta T=5.3(265)$ & Not available & $\begin{array}{l}4 \text { Oct } 2300 \\
5 \text { Oct } 0200\end{array}$ \\
\hline 2 & 5 Oct: 2200 & 6 Oct: 1300 & $\begin{array}{l}\mathrm{S} \text { Jet } \sim 10 \mathrm{~m} \mathrm{~s}^{-1} \text {, near } 110 \mathrm{~m} \mathrm{AGL;} \\
\text { turbulence, } \mathrm{K}-\mathrm{H} \text { billows; morning } \\
\text { transition. } \Delta T=6.7 \text { (335) }\end{array}$ & 6 Oct $0100-0430$ & $\begin{array}{l}6 \text { Oct } 0430-0715 \\
6 \text { Oct } 1100-1300\end{array}$ \\
\hline 3 & 9 Oct: 2200 & 10 Oct: 1300 & $\begin{array}{l}W \text { jet } \sim 10 \mathrm{~m} \mathrm{~s}^{-1}, 60-120 \mathrm{~m} \mathrm{AGL} . \\
\Delta T=6.2(310)\end{array}$ & 10 Oct $0200-0315$ & Not available \\
\hline 4 & 10 Oct: 2200 & II Oct: 1300 & $\begin{array}{l}\text { Postfrontal ENE jet } \sim 17 \mathrm{~m} \mathrm{~s}^{-1} \\
100-200 \mathrm{~m} \mathrm{AGL} . \Delta T=4.0(200)\end{array}$ & II Oct 1030-1300 & Not available \\
\hline 5 & II Oct: 2200 & 12 Oct: 1300 & $\begin{array}{l}\text { Weak surface flow with strong flow } \\
\text { aloft to } 17 \mathrm{~m} \mathrm{~s}^{-1} \text { near } 250 \mathrm{~m} \mathrm{AGL} \text {. } \\
\text { Organized } \mathrm{KH} \text {-like and wavelike } \\
\text { structures observed. } \Delta T=5.1 \text { (255) }\end{array}$ & $\begin{array}{l}12 \text { Oct } 0400-0800 \\
12 \text { Oct } 0900-1300\end{array}$ & $\begin{array}{l}12 \text { Oct } 0000-0200 \\
12 \text { Oct } 1000-1300\end{array}$ \\
\hline 6 & 13 Oct: 2200 & 14 Oct: 1300 & $\begin{array}{l}\text { ENE jet } \sim 9-12 \mathrm{~m} \mathrm{~s}^{-1}, 120-180 \mathrm{~m} \text { AGL. } \\
\text { Turbulence/wave sheets; gravity waves; } \\
\text { turbulence bursting; KH activity; } \\
\text { dissipation of LLJ. } \Delta T=5.4(270)\end{array}$ & $\begin{array}{l}13 \text { Oct } 0400-0830 \\
13 \text { Oct } 0930-1300\end{array}$ & $\begin{array}{l}13 \text { Oct } 0100-0400 \\
13 \text { Oct } 1000-1300\end{array}$ \\
\hline 7 & 17 Oct: 2200 & 18 Oct: 1300 & $\begin{array}{l}\text { Surface-based turbulent event. } \\
\text { N-E-SE jet } \sim 10 \mathrm{~m} \mathrm{~s}^{-1}, 200-300 \mathrm{~m} \\
\rightarrow>100 \mathrm{~m} \mathrm{AGL} . \Delta T=5.9(295)\end{array}$ & $\begin{array}{l}18 \text { Oct } 0200-0445 \\
18 \text { Oct } 0945-1200\end{array}$ & $\begin{array}{l}17 \text { Oct } 2300- \\
18 \text { Oct } 0200 \\
18 \text { Oct } 1030-1300\end{array}$ \\
\hline 8 & 19 Oct: 2200 & 20 Oct: 1300 & $\begin{array}{l}\text { S-SW jet } \sim 11 \mathrm{~m} \mathrm{~s}^{-1}, 60-120 \mathrm{~m} \mathrm{AGL} . \\
\text { Little wave activity. } \Delta T=7.1(355)\end{array}$ & 20 Oct $0800-1300$ & $\begin{array}{l}19 \text { Oct } 2230- \\
20 \text { Oct } 0130 \\
20 \text { Oct } 1000-1300\end{array}$ \\
\hline 9 & 20 Oct: 2200 & 21 Oct: 1300 & $\begin{array}{l}\text { S-SW jet } \sim 10-12 \mathrm{~m} \mathrm{~s}^{-1}, 100- \\
200 \mathrm{~m} \text { AGL. A fossil turbulence event } \\
\text { and nearly continuous, weak surface- } \\
\text { based turbulence. } \Delta T=4.8(240)\end{array}$ & $\begin{array}{l}20 \text { Oct } 2300-0300 \\
\text { second flight }\end{array}$ & $\begin{array}{l}20 \text { Oct } 2330-0230 \\
\text { second flight }\end{array}$ \\
\hline 10 & 22 Oct: 2200 & 23 Oct: 1300 & $\begin{array}{l}\text { No jet. Consistent dissipation at } \\
\text { about } 200 \mathrm{~Hz} . \Delta T=5.5(275)\end{array}$ & Not available & 23 Oct $1000-1400$ \\
\hline 12 & 26 Oct: 1900 & 27 Oct: 1300 & $\begin{array}{l}\text { Evening transition. No jet. } \\
\Delta T=5.0(250)\end{array}$ & $\begin{array}{l}26 \text { Oct } 2215- \\
27 \text { Oct } 0145 \\
27 \text { Oct } 0400-0645\end{array}$ & Not available \\
\hline
\end{tabular}

exceptional resolutions for operational forecasting and our operation benefited significantly from their presence. The model setup for these forecasts is avail- able online (www.joss.ucar.edu/cases99) to those using the CASES-99 dataset who also wish to use RAMS for case study investigations or other purposes. 
TABLE 3. CASES-99 nights with inertial oscillations beginning 0000 UTC and lasting for $14-16 \mathrm{~h}$ at the boundary layer profilers located at B: Beaumont, W: Whitewater, O: Oxford, E: EI Dorado, and S: Smileyberg (see Fig. 2 for locations).

\begin{tabular}{|c|c|c|c|c|c|}
\hline $\begin{array}{l}\text { Even } \\
\text { No. }\end{array}$ & $\begin{array}{c}\text { Date } \\
\text { (Julian date) }\end{array}$ & $\begin{array}{l}\text { Sites with } \\
\text { IOs }\end{array}$ & $\begin{array}{l}\text { IOP } \\
\text { No. }\end{array}$ & $\begin{array}{l}\text { LLJ characteristics } \\
\text { overnight }\end{array}$ & $\begin{array}{l}\text { GLASS winds } \\
\text { available below } \\
120 \mathrm{~m}\end{array}$ \\
\hline I & $\begin{array}{l}4-5 \text { Oct } \\
(278)\end{array}$ & All & 1 & Weak LLJ & No \\
\hline 2 & $\begin{array}{l}5-6 \text { Oct } \\
(279)\end{array}$ & All & 2 & LLJ at $100 \mathrm{~m}$ & Sporadically \\
\hline 3 & $\begin{array}{l}7-8 \text { Oct } \\
(28 I)\end{array}$ & All & N/A & Slab acceleration & Yes \\
\hline 4 & $\begin{array}{l}10-11 \text { Oct } \\
(284)\end{array}$ & All & 4 & $300 \mathrm{~m}, 12-18 \mathrm{~m} \mathrm{~s}^{-1}, 50^{\circ}-100^{\circ}$ & Yes \\
\hline 5 & $\begin{array}{l}\text { II-12 Oct } \\
\quad(285)\end{array}$ & W, O, E, S & 5 & $\begin{array}{c}200-300 \mathrm{~m}, 10-15 \mathrm{~m} \mathrm{~s}^{-1} \\
180^{\circ}-210^{\circ} \mathrm{C}\end{array}$ & No \\
\hline 6 & $\begin{array}{l}12-13 \text { Oct } \\
(286)\end{array}$ & All & $\mathrm{N} / \mathrm{A}$ & $\begin{array}{c}300-400 \mathrm{~m}, 15-20 \mathrm{~m} \mathrm{~s}^{-1} \\
200^{\circ}-250^{\circ}\end{array}$ & N/A \\
\hline 7 & $\begin{array}{l}\text { 13-14 Oct } \\
(287)\end{array}$ & $\mathrm{B}, \mathrm{O}, \mathrm{E}, \mathrm{S}$ & 6 & $200 \mathrm{~m}, 12 \mathrm{~m} \mathrm{~s}^{-1}, 120^{\circ}$ & $\begin{array}{c}\text { None but at } 0300 \text { for } E \\
\text { and } S\end{array}$ \\
\hline 8 & $\begin{array}{l}22-23 \text { Oct } \\
(296)\end{array}$ & All & 10 & & Only after 0700 UTC \\
\hline 9 & $\begin{array}{l}27-28 \text { Oct } \\
(301)\end{array}$ & All & N/A & $400 \mathrm{~m}, 20 \mathrm{~m} \mathrm{~s}^{-1}, 200^{\circ}$ & Only at II 00 UTC \\
\hline
\end{tabular}

The RAMS forecasts for these clear, generally weak surface wind nights were made available each afternoon for that night and the following night. Interestingly, RAMS, like most modeling systems today, is subject to the known parameterization errors in dynamically stable near-surface conditions described previously in the project background. Thus, we should expect that these forecasts should be error prone and, indeed, quite often the surface features were in error (i.e., surface temperature) and the observed heterogeneity of the NBL could not be captured. However, RAMS was quite frequently able to portray the orientation and development of a near-surface jet from 50 to $250 \mathrm{~m}$ AGL that were then verified by observations during an IOP. This information was otherwise unavailable from any other resource, and was often used to prepare observational strategies during the field phase.
Numerical modeling within CASES-99. The CASES-99 datasets will enable investigators to address some of the primary deficiencies of current model parameterizations in the stable boundary layer. While the focus is primarily on turbulent diffusion and surface layer parameterization, a number of physiographic parameterizations could also be validated. These parameterizations are used in models from the global to micro- $\gamma$ scale, and in both operational and research environments. Thus, the common goal of those researchers using numerical techniques is to combine various approaches to achieve the most comprehensive improvements to the model when the atmosphere is statically and dynamically stable, on average. The various types of numerical modeling activities anticipated as a part of CASES-99 are described below. It is anticipated that careful merging of theoretically 
based modeling with mesoscale, LES and DNS techniques, and quantitative comparison with the comprehensive field phase measurements will produce scientific advances in the ability to model and parameterize stable NBL phenomena.

MesosCale modeling. Although no results are shown here, post-field phase mesoscale numerical simulations will use a variety of mesoscale models (e.g., RAMS, above), depending on the investigator, to describe the coupled land-atmosphere system, boundary layer fluxes, and NBL structure observed by CASES-99 instrumentation. Such models are capable of capturing large-scale forcing on a larger grid and using grid nesting to telescope down to the scales of interest, but are hindered by deficiencies in parameterization capability during conditions where turbulence is suppressed by stratification and weak wind or weak wind shear. These models use a variety of parameterizations-radiation parameterization, a soil/vegetation model (temperature and moisture) and can ingest high-resolution physiographic data (terrain heights, vegetation, soil type, and land percentage), all of which will affect NBL evolution (Pielke et al. 1992). Mesoscale models will be utilized in four main ways: 1) to reconstruct, at very high horizontal $[O(100) \mathrm{m}$ grid spacing and vertical $O(10) \mathrm{m}$ grid spacing] resolution, the micro- $\gamma$ scale features of the NBL for case nights of interest from CASES-99, considering also item 3 (below); 2) to provide guidance (shear values, initial Richardson number profiles, etc.) to the LESs and DNSs described below (with due respect to the following); and 3) to reveal the deficiencies of the existing stable surface layer and subgridscale parameterizations; 4) in idealized studies of various NBL features.

For case study reconstruction and testing of the stable surface layer and subgrid-scale parameterizations, emphasis will be placed on comparison and validation against measurements from the CASES-99 field experiment. This will provide the foundation for analysis of simulation quality and the performance of the parameterizations. Inaccuracies in the simulation of the very stable surface layer will be evaluated to pose new solutions to that problem, as hypothesized by various CASES-99 participants, and will hopefully lead to the improvement or development of entirely new parameterization schemes.

LARGE EDDY SIMULATION. LESs are planned by some investigators for more detailed investigation of several aspects of stably stratified, surface/boundary layer turbulence, such as the nature of intermittence, coher- ent structures, and fluxes in stably stratified planetary boundary layer (PBL) flows and to explore how these PBLs differ from their unstable and neutral counterparts. In order to carry out this research, a critical review of subgrid-scale (SGS) modeling practices in LES is being undertaken since one can anticipate that the current SGS models, developed primarily for unstable and neutral flows, are inadequate for the stable regime. Because the optimal simulation scale of the LES lies between that of the mesoscale model and that of the DNS, simulated stable NBLs using LES are an important part of determining the flaws in SGS parameterization (Saiki et al. 2000). With regard to the issue of SGS modeling, the question arises as to how to parameterize the effects of small eddies (smaller than typical LES grid volume in LES for stably stratified turbulence). Some LES solutions are very sensitive to the stability corrections. In combination with the mesoscale modeling analysis, reformulation of these parameterizations for the stable NBL should be possible with sensitivity case studies of CASES-99 IOPs in comparison with its supporting measurements. Similarly, comparisons with DNS will show where, perhaps, the unrealistic viscosity in the DNS fails to allow the development of sufficiently chaotic features. Such comparisons will ensure the proper interpretation of the dynamical evolution in all three modeling techniques.

DiRECT NUMERICAL SIMULATION. A central science goal of CASES-99 is quantifying the role of intermittency in turbulent mixing and transport. The causes of the intermittency can be Kelvin-Helmholtz and gravity wave instabilities that are in turn caused by largerscale forcing such as drainage flows, elevated jet maxima, and radiative fluxes. DNS of the initiation of these instabilities and the evolution of the resultant turbulent layers is uniquely suited to quantifying the intermittency because DNS is not subject to the turbulence parameterization errors, and is adequate if executed at sufficiently high Reynolds number, Re (Fernando 1991). The large-scale flows observed during the CASES-99 field phase determine the initial conditions for the DNS, and hot-film, sonic anemometer and hot-wire measurements of turbulence statistics can validate the subsequent evolution calculated by DNS. Focused case study simulations using the DNS technique will examine flow instability within and above the NBL; the occurrence, intensity, and intermittency of turbulence and its penetration into the observed CASES-99 stable NBL; and the structure of, and the turbulence fluxes accompanying, such penetration events. Since DNS is subject to using Re that 
are almost always smaller than those measured in the NBL (except at very small scales; Muschinski and Wode 1998), one can question its applicability here. However, current computational advances have allowed DNS to use $10^{4}<\operatorname{Re}<10^{5}$, yielding a buoyancy/ inertial subrange of turbulence spanning a decade or more, and enabling assessment of turbulent fluxes and transport accompanying such events (Werne and Frits 1999, 2001). These simulations will be used to further evaluate and improve parameterizations in LES and mesoscale models and allow high spectral frequency comparisons to CASES-99 field data. Because it calculates turbulence directly, the DNS technique has the unique ability to quantify all terms in the fundamental budgets, even those that cannot be measured. This is especially important with the intermittent turbulence in stratified flows, where locally strong turbulence and sharp thermal or constituent gradients may lead to strong, spatially, and temporally localized mixing and transport, which may differ greatly from mean turbulence statistics. In combination with the LES and mesoscale models, DNS should contribute significantly to the evaluation of deficiencies in parameterizations subjected to stable atmospheric conditions.

PRELIMINARY RESULTS. IOP-7, I 8 October 1999, intermittent phenomena. IOP-7 was characterized by two density current passages and another event with some density current characteristics around 1200 UTC. This CASES-99 IOP serves as a prime example of the variety of phenomena that populate and influence the evolution of the primarily dynamically stable NBL, and is being emphasized by a number of investigators. Data obtained during this eventful overnight period are shown below to contribute significantly toward the achievement of the scientific goals described in the field experiment description. Whereas the first two events had typical characteristics of density currents, the third event near 1200 UTC had unusual characteristics.

TOWER MEASUREMENTS. The high vertical resolution thermocouples captured many interesting intermittent mixing events, such as density currents and gravity waves. One of the density currents passed through the main tower on 18 October 1999 at 0140 UTC (17 October 1999, at 2040 CDT; Fig. 6). The density current passage is marked by the appearance of cold, moist, and high carbon dioxide air with significant vertical wind shear from the ENE. As the cold air passed by, the wind direction switched from the ENE to NNE, then back to the ambient wind direction
(Fig. 6). The wind direction change is in response to the local pressure adjustment associated with the density current. The downward propagation of the $1^{\circ}-$ $4^{\circ} \mathrm{C}$ temperature drop indicates that the head of the density current was elevated from the ground surface as Fig. 6 illustrates. The cold, moist, and high $\mathrm{CO}_{2}$ air intrusion at the higher level leads to thermal instability, resulting in large upward heat transfer, downward moisture and $\mathrm{CO}_{2}$ transfer between 30 and $40 \mathrm{~m}$ (the "upside-down" boundary layer), and large temperature oscillations at the upper levels. While at the lower level, where the temperature profile was still stable, there was downward heat transfer and upward moisture and $\mathrm{CO}_{2}$ transfer, as expected in a typical stable nocturnal boundary layer.

Associated with the density current, there was a wind surge lagging behind the cold air intrusion. As the wind surge propagated downward, the wind shear increased especially close to the ground surface, where the wind speed remained near zero. As a result, turbulence is generated by strong wind shear (middle two panels, Fig. 6). As the stratification at the upper level is reestablished quickly after the relatively cold current passes by, the turbulence is significantly reduced. In contrast, at lower levels shear-generated turbulence increases. The stronger stratification after the current passes is related to downward motion behind the head of the density current.

Spectral analysis (not shown) based on the Haar wavelet transform (Howell and Mahrt 1997) indicates that the cold air intrusion triggered large temperature oscillations with the gravity wave period around $12 \mathrm{~min}$ at all heights. The strong wind surge followed the density head generated the strong shear turbulence with the eddy size much smaller than the early gravity waves. This analysis of the mixing event illustrates that the unprecedented high vertical resolution thermocouples, and sonic anemometers captured the detailed structure of the density current, especially where the density head leads to a upside-down nocturnal boundary layer. Further discussion of this event can be found in Sun et al. (2002).

Kite/Balloon INFORMATION. An example of one interesting, but as yet unexplained, phenomenon was captured by a tethered launching system (TLS; Balsley et al. 1992, 1994) flight during a period when turbulence activity at low altitudes was being measured by aircraft. Figure 7, which was obtained during a TLS ascent near 1155 UTC 18 October, depicts highfrequency temperature fluctuations between 30 and $55 \mathrm{~m}$ AGL measured by three separate sensor packages separated by $6 \mathrm{~m}$ and ascending at about $0.4 \mathrm{~m} \mathrm{~s}^{-1}$. 

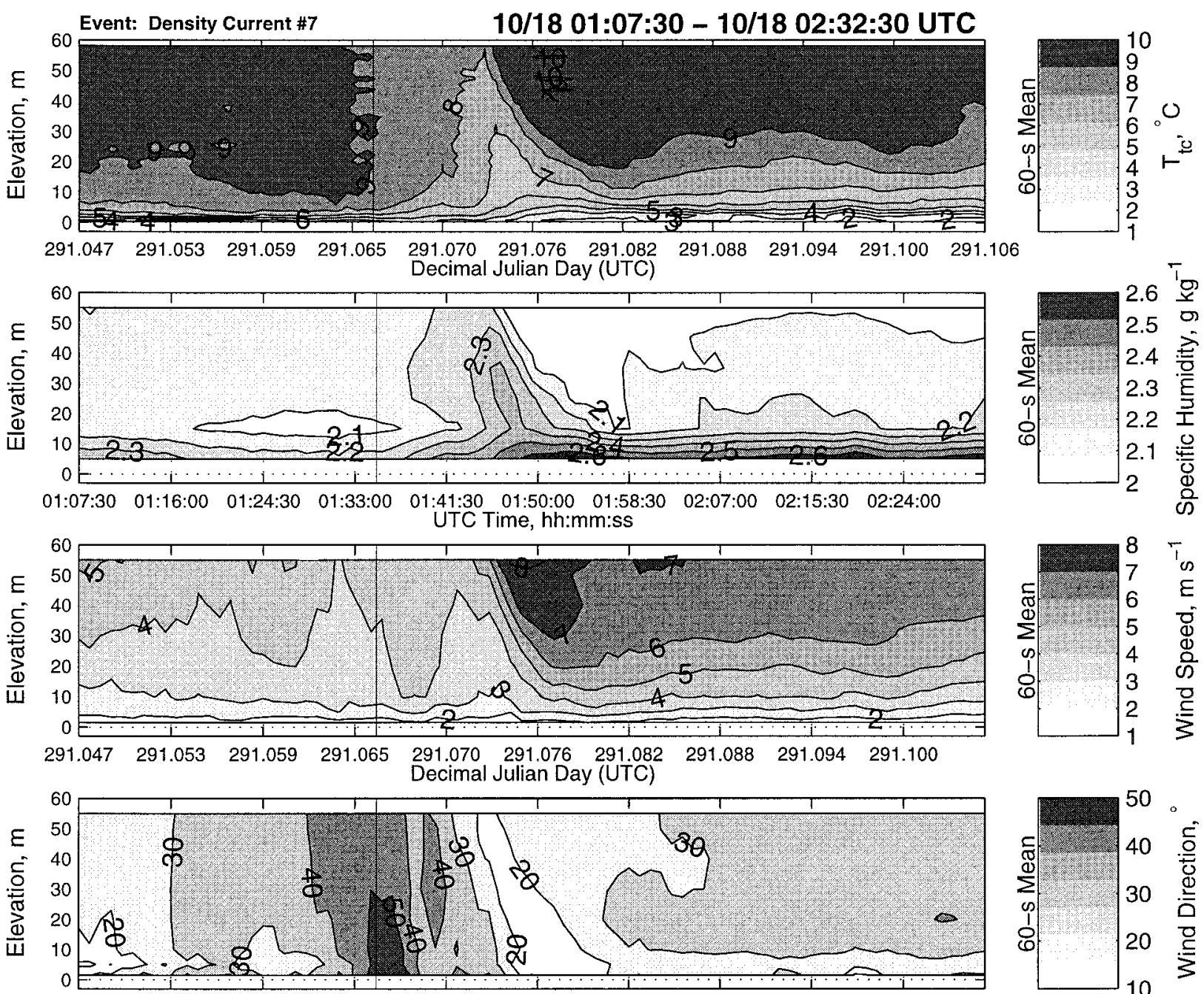

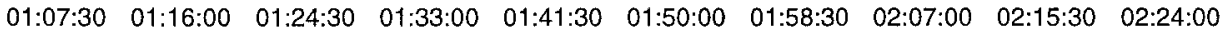
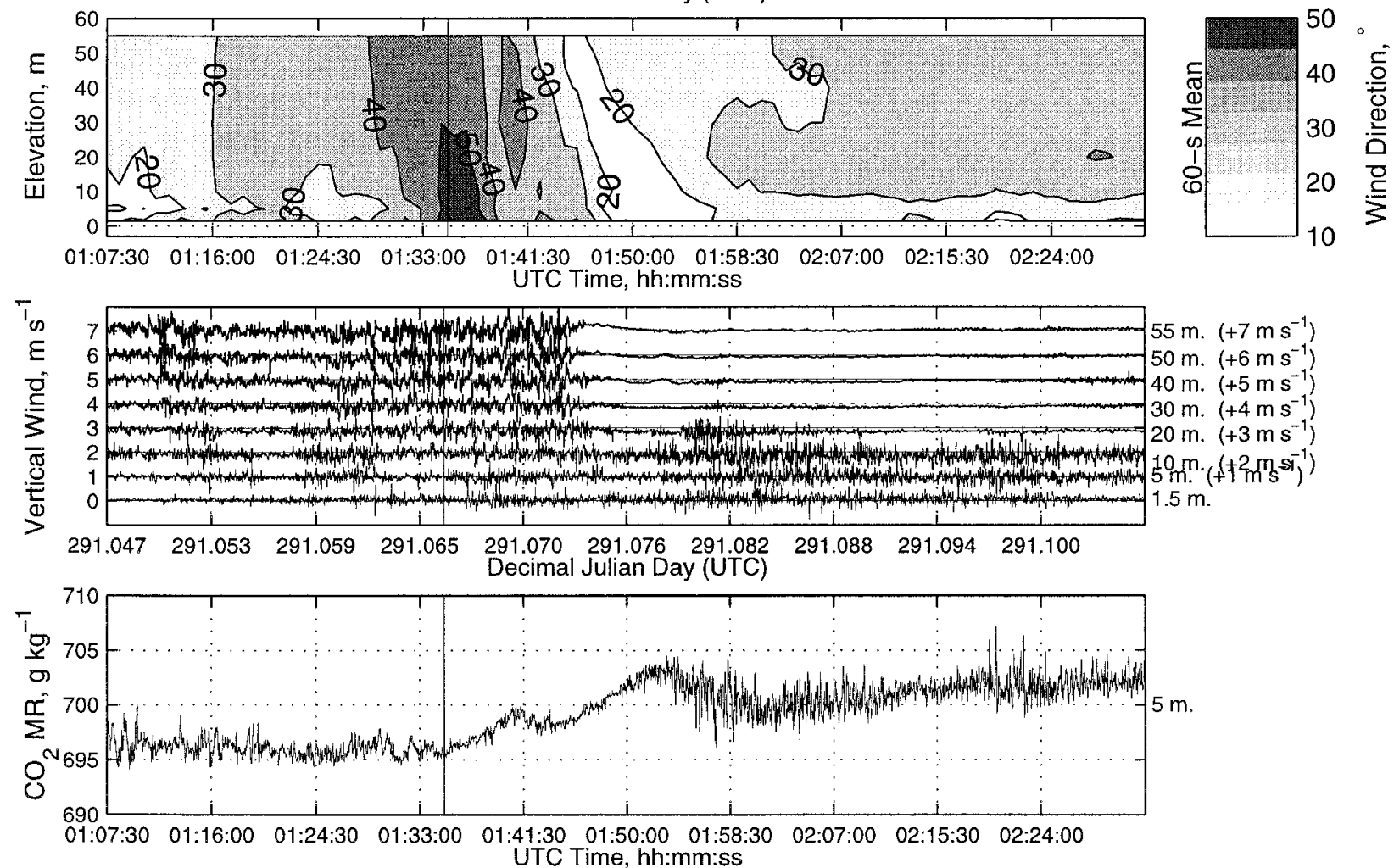

Fig. 6. The time-height plot of various atmospheric variables during the density current on 18 Oct 1999, near 0200 UTC, where the air temperature, the specific humidity, the wind speed, the wind direction, the vertical velocity, and the carbon dioxide concentration at $5 \mathrm{~m}$ are plotted from the top to the bottom, respectively. 
Although the TLS obtained data to $400 \mathrm{~m}$, only the lower portion of these profiles is presented here. The unusual feature of these results is the fairly intense $\left(\sim 0.3^{\circ} \mathrm{C}\right)$ sinuous temperature fluctuations with a vertical scale of only a few meters that are apparent on all the sensors. These fluctuations did not occur on earlier ascents. They were also observed on other sensors (low-frequency temperature sensors and Pitot tubes) on the same packages. One point of interest is the coherence of these fluctuations during the 30-s interval between the passage of the first and last package through the region. A second point is the apparent upward motion of the envelope of the fluctuations of about $1 \mathrm{~m}$. This suggests either a true vertical motion of the structure of a few centimeters per second, or a tilted horizontal structure advected past the sensors, with a $1-\mathrm{m}$ tilt in $\sim 150 \mathrm{~m}\left(30 \mathrm{~s} \times 5 \mathrm{~m} \mathrm{~s}^{-1}\right.$ wind speed). The TLS data alone are insufficient to resolve this question.

The relative turbulence intensity levels in the 45-50-m region before and after the Fig. 7 profiles are shown in Fig. 8. Figure 8 (top) shows high-frequency temperature fluctuation spectra from the cold-wire sensors on package No. 3. Note that the spectral levels about $1 \mathrm{~h}$ prior to the Fig. 7 profile are at least a factor of 50 weaker than those obtained about $1 \mathrm{~h}$ later. A somewhat smaller increase, yet still more than a factor of 20, is apparent in Fig. 8 (bottom), which shows spectra for the turbulent wind speed fluctuations (from the hot-wire sensor) for the same periods. Note that comparable turbulent levels above $55 \mathrm{~m}$ during this period did not exhibit such an increase. On the other hand, turbulence fluctuations at higher heights during other periods were at times much more variable, and occasionally quite intense.

FIG. 8. (top) Spectra of high-frequency temperature and (bottom) wind speed fluctuations obtained roughly I $h$ before and after the results shown in Fig. 7, during IOP7. Note the marked increase in turbulence levels in both sets of spectra.

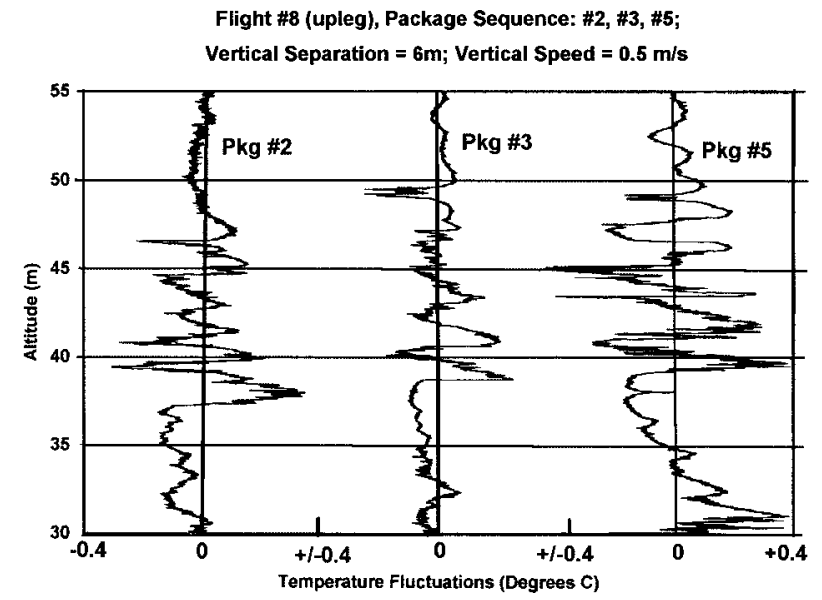

FIG. 7. Vertical profiles of high-frequency temperature fluctuations observed by three separate probes on the tethered lifting system ascending sequentially through the 30-55-m height range at $0.4 \mathrm{~m} \mathrm{~s}^{-1}$. These observations were taken near I I 55 UTC I 8 Oct during IOP-7.

Temperature Fluctuation Spectra: Flight \#8 Package \#3 Height $=45.50 \mathrm{~m}$; Start Time $=10.74$ GMT \& 12.74 GMT
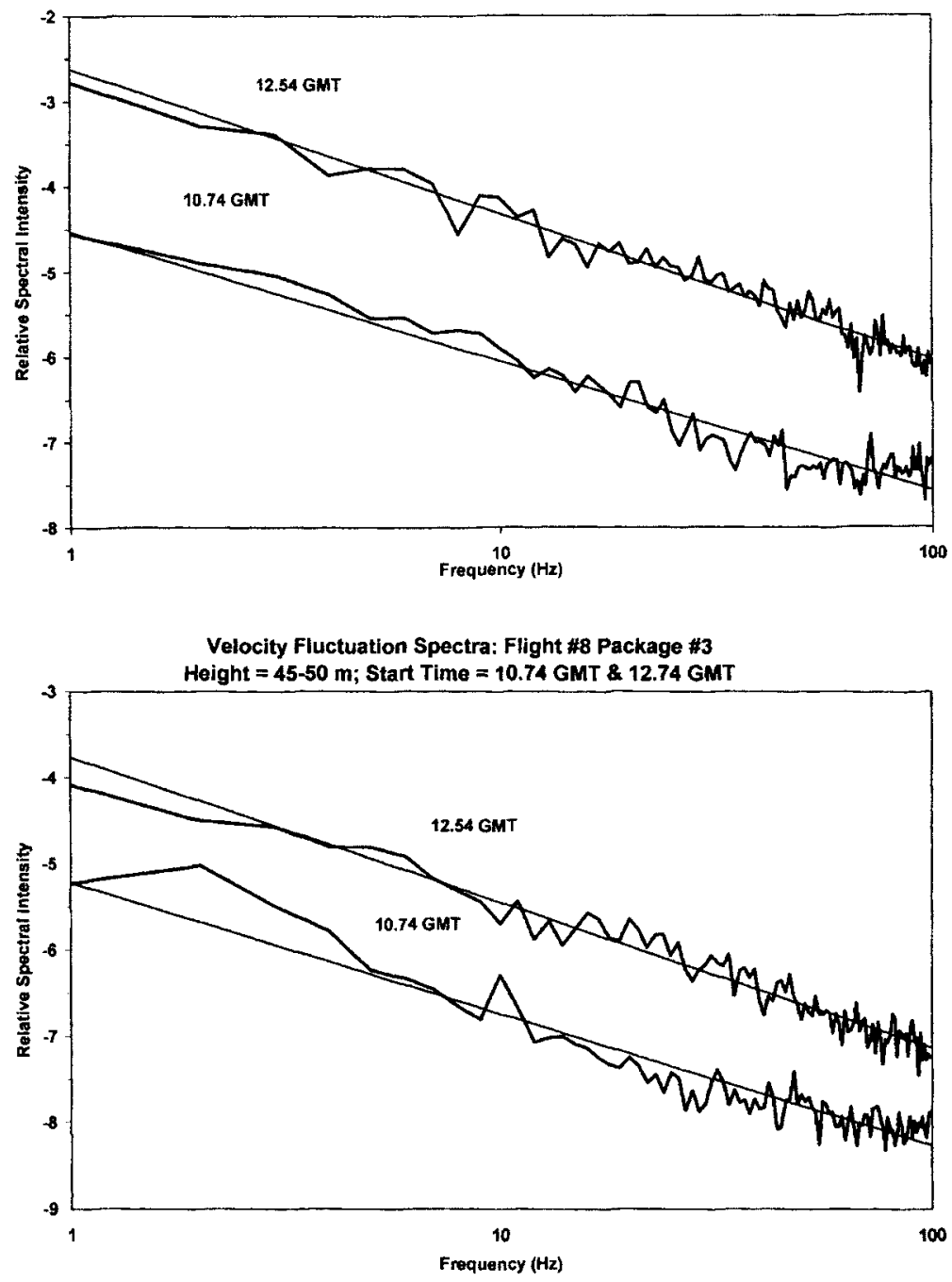
AIRCRAfT Information. Data from the Wyoming King Air are shown in Fig. 9 for the period 1212-1217 UTC 18 October 1999 where zero on the $x$ axis represents the meridional location of the $60-\mathrm{m}$ tower. Note in Fig. 9 (bottom) that the altitude AGL flown by the aircraft was quite low and allows for a reasonable comparison with instruments sampling between 40 and $100 \mathrm{~m}$. Plots of $u$ and $v$ indicate that NE flow existed at all levels sampled by the King Air during this leg, with significant variability at meridional distances $0,+7$, and $+10 \mathrm{~km}$. These localized events are accompanied by significant vertical wind speeds and rapid variability through a range exceeding $|0.5| \mathrm{m} \mathrm{s}^{-1}$. As stated above these events corresponded to moderate turbulence reports from airborne personnel. Efforts are underway to better correlate the variety of measurement platforms sampling these events from this IOP.

THE HORIZONTAL EXTENT OF INTERMITTENT EVENTS—GULLY DATA. Among some of the interests of the CASES-99 investigators is the horizontal extent of intermittent turbulence events in the NBL. Figure 10 shows observations from the gully to the SW of the 60-m tower as drawn in Fig. 3. Although the gully is $\sim 1 \mathrm{~km}$ from the $60-\mathrm{m}$ tower where three primary events were measured and the gully experienced very strong static stability with persistent katabatic flow on this night, each of the three events that occurred during IOP-7, as measured by the tower, influenced gully flow. Note the sudden oscillation in wind direction during three periods in Fig. 10; 2300 CDT (0400 UTC), 0130 CDT ( 0530 UTC), and again at 0530 CDT (1030 UTC). Surprisingly, such influences on apparently well-established katabatic flow has been reported by Poulos (1996) for much longer, deeper, and wider valleys in the Rocky Mountains. This interesting result suggests that intermittent turbulent events in the NBL are not isolated horizontally in their influence. These influences are manifested by changes in momentum characteristics in the gully, where katabatic flow is temporarily interrupted on three separate occasions.
October 18, 1999, 12:12-12:17 UTC
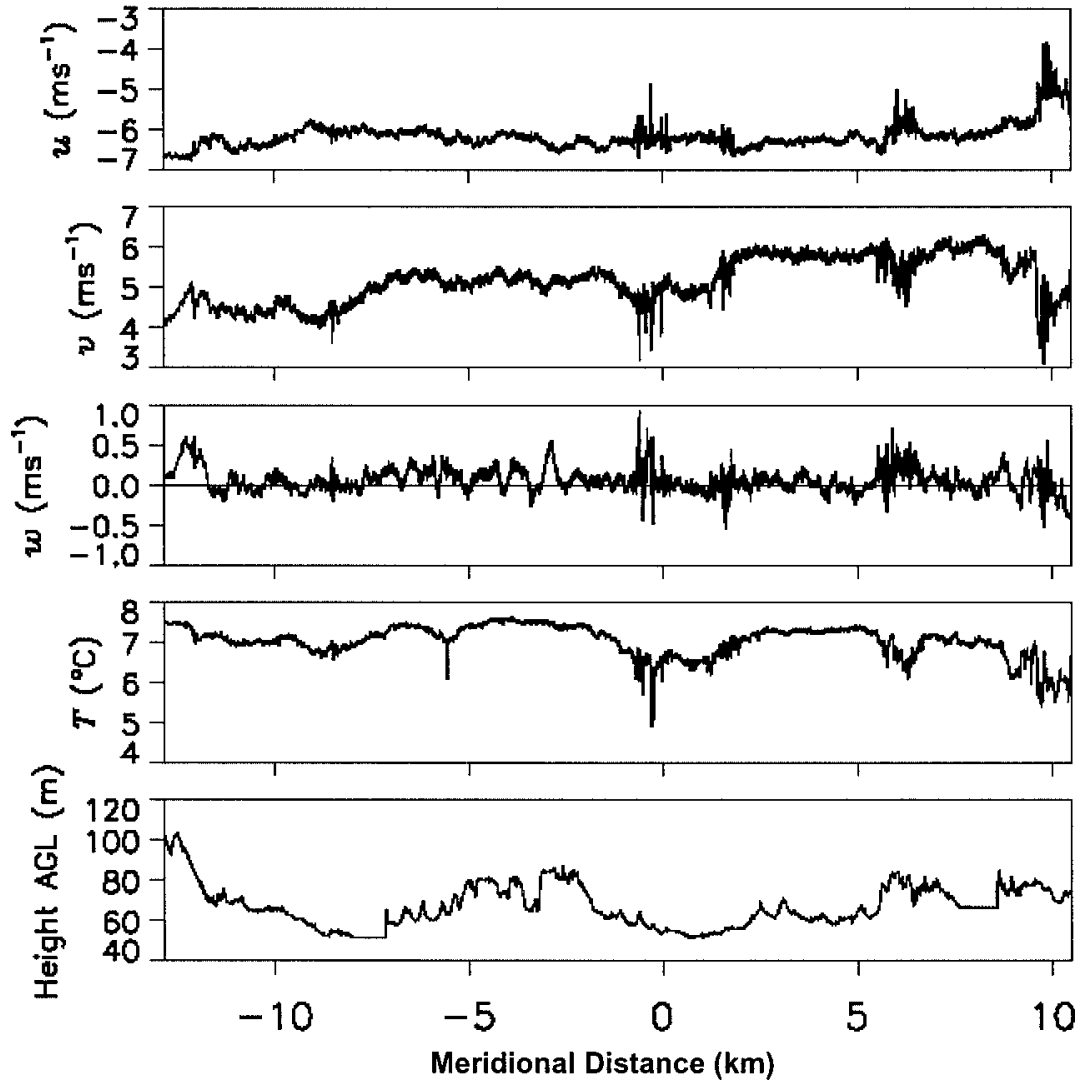

FIG. 9. (top to bottom) $u, v, w, T$, and height AGL vs meridional distance $(\mathrm{km})$ from a single leg of the Wyoming King Air during IOP-7 near sunrise. Note the very low flight levels and intermittent periods of high variability encountered by the aircraft.
IOP-2, 6 October 1999, 05150545 UTC, short-lived instability. The NOAA HRDL and in situ tower sensors captured what appeared to be waves and turbulence associated with a shear instability propagating in a horizontal direction over the CASES-99 field site between 0520 and 0545 UTC (23202345 CDT) on 6 October 1999. A radiosonde observation taken at $0300 \mathrm{UTC}$ at a site located $16 \mathrm{~km}$ north-northwest of the main site is displayed in Fig. 11. The flow is southerly, and the positive shear layer and inversion are confined to approximately a depth of $85 \mathrm{~m}$. The layer Richardson number for this flow is subcritical at 0.15 . The later measurements at low levels at the main site do not indicate any significant departures from these conditions. This event is investigated in considerably greater detail in Blumen et al. (2001) and Newsom and Banta (2001, manuscript submitted to $J$. Atmos. Sci.). 
A 1-h time series of the temperature and horizontal and vertical wind speeds is presented in Fig. 12. The billow event is characterized by the larger amplitude, high-frequency responses during the approximate period $0520-0545$ UTC. Although the atmosphere appears to be in a state that promotes instability a few hours before the 0520 UTC event occurred, the observing systems in place did not record any other event that could be related to the onset of shear instability. This circumstance does not violate the theoretical underpinnings of the derived stability criterion, Ri $<0.25$ (Howard 1961). The condition, $\mathrm{Ri}<0.25$, is a necessary but not sufficient condition for the instability to occur. Events similar to the one observed may, however, have occurred outside the range of the CASES-99 observing systems. A low-level jet was established during the observation period, with peak winds of $9 \mathrm{~m} \mathrm{~s}^{-1}$ at $120 \mathrm{~m}$ AGL. The jet structure, as determined by a VAD analysis of the lidar data, was characterized by a strong wind shear between the surface and $\sim 85 \mathrm{~m}$, a jet maximum at $\sim 120 \mathrm{~m}$, and a gradual tapering of the profile above that level. Winds at the surface were light $\left(<2 \mathrm{~m} \mathrm{~s}^{-1}\right)$. Based on high-rate tower data from sonic anemometers and thermocouples, the mean temperature gradient between the surface and the top of the $60-\mathrm{m}$ tower was approximately $140^{\circ} \mathrm{C} \mathrm{km}^{-1}$ about $1 \mathrm{~h}$ prior to the event. During the $15-\mathrm{min}$ period prior to the event, the mean wind shear between $30 \mathrm{~m}$ and the top of the tower was approximately $0.17 \mathrm{~s}^{-1}$. A series of large intermittent bursts in turbulence began at about 0520 UTC and persisted until about 0545 UTC. The most intense bursts occurred above the 20-m tower level.

Between 0525 and 0542 UTC HRDL performed shallow vertical-slice scans in the general direction of the mean flow. The scan plane was oriented at an azimuth of $10^{\circ}$ and the lidar scanned from $0^{\circ}$ to $10^{\circ}$ in elevation at a rate of $0.33^{\circ} \mathrm{s}^{-1}$, producing in a full $10^{\circ}$ scan in $30 \mathrm{~s}$. The lidar recorded 33 sequential scans during this period. Figure 13 shows a representative HRDL scan during the event. Coherent propagating wave structures are clearly evident in animations of all scans (see online at www.etl.noaa.gov/ ypichugina/

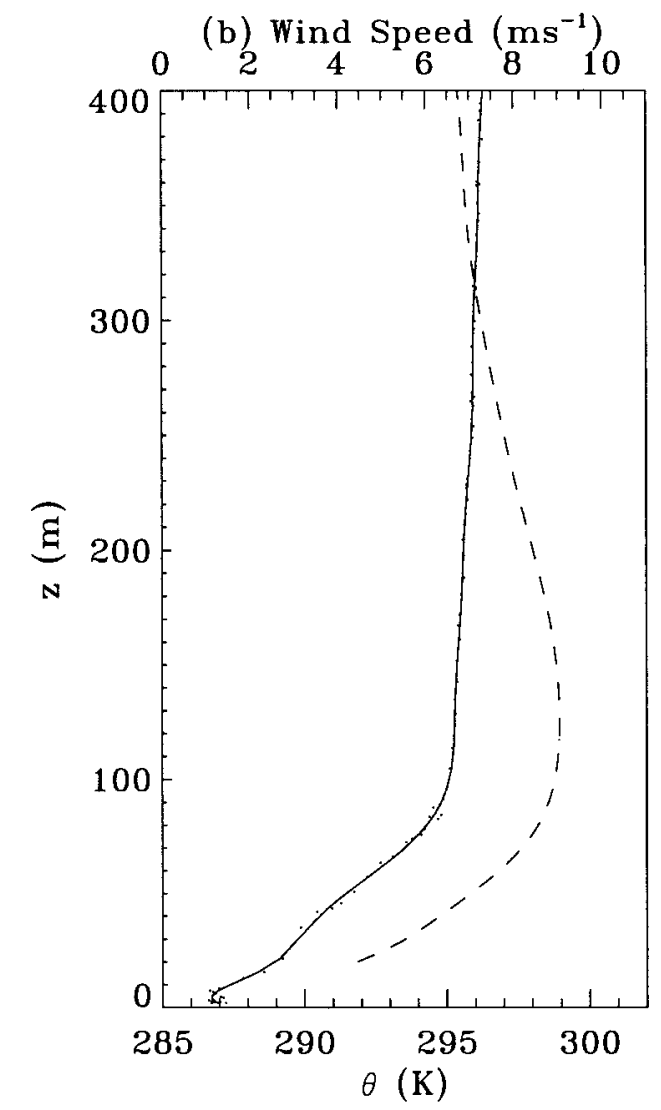

Fig. I I. Potential temperature (solid line) and wind speed (dashed line) from the 0300 UTC sounding taken at El Dorado on 6 Oct 1999 during IOP-2. Strong shear and low Ri contributed to conditions conducive to Kelvin-Helmholtz billow development. 

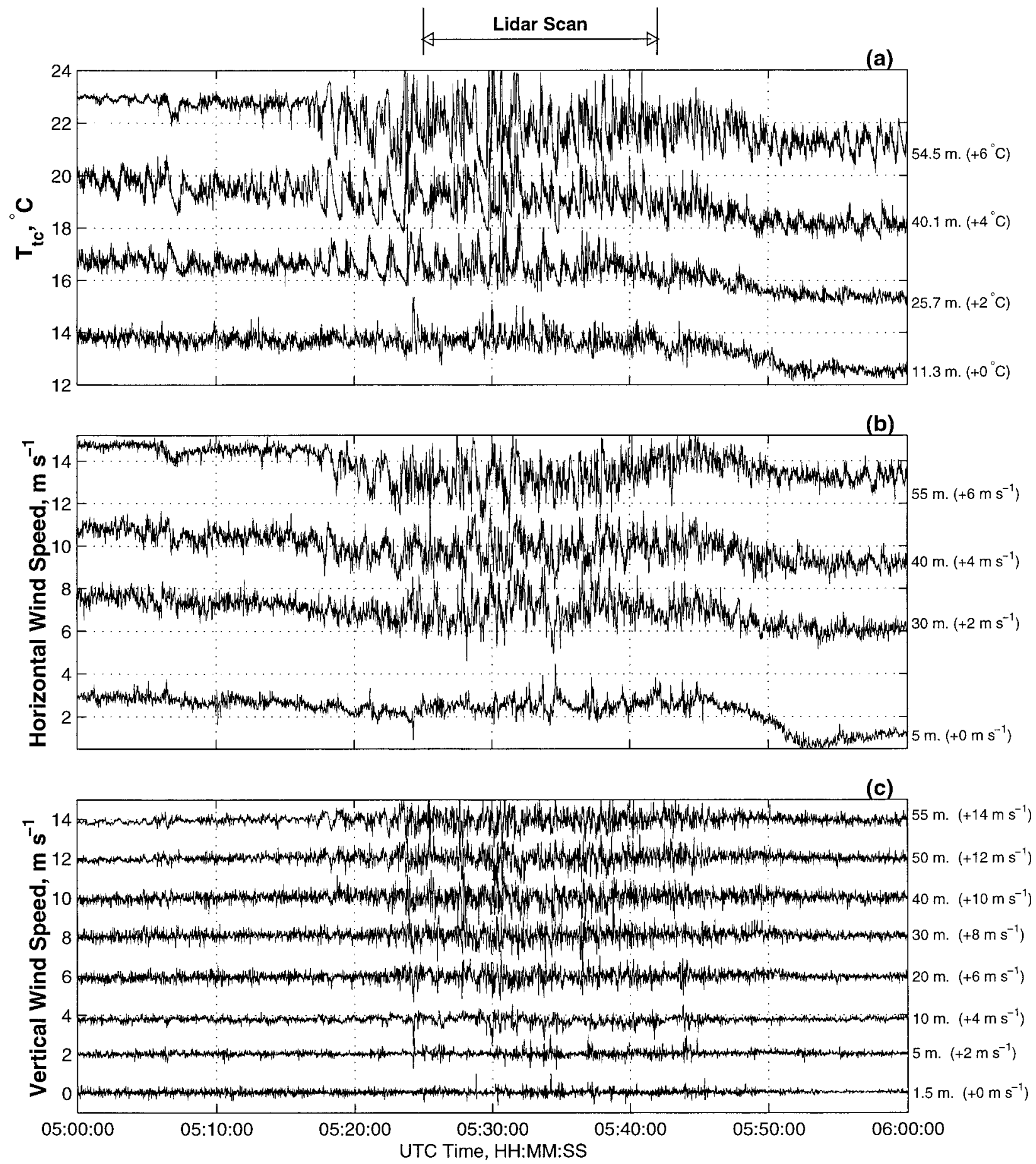

FIG. I2. Various time series from 6 Oct 1999. (a) Thermocouple temperature, (b) sonic anemometer horizontal wind speed, and (c) sonic anemometer vertical wind speed. The instrument level and quantity of data have been shifted to reveal structures.

b_6.html, Animation 1, courtesy NOAA-ETL). In several scans, the lidar observations show distinct evidence of what appear to be overturning wave structures or "billows" with a phase speed of $5.5 \pm 0.8 \mathrm{~m} \mathrm{~s}^{-1}$. The wavelength of these features based on both visual inspection and spectral analysis, is between 350 and
$400 \mathrm{~m}$, with the strongest wave activity between 40 and $70 \mathrm{~m}$ AGL. The first relevant scale after a sheared layer of thickness $h$ becomes unstable is the wavelength of maximum amplification, $L$ (e.g., Miles and Howard 1964; Scorer 1997). The measured $L$ for this billow is $400 \mathrm{~m}$, which when used in the theory of 
Scorer (1997) gives a wave amplitude of $32 \mathrm{~m}$. This value compares favorably to the observed billow height, although other aspects of Scorer's (1997) theory are less well matched. However, the work of De Silva et al. (1996) suggests that this billow may be in an early growth stage, rather than the final mixed state (Thorpe 1973). Perhaps the mixing efficiency within a billow may be quite different under actual environmental conditions.

Tower measurements clearly indicate a substantial increase in turbulent activity between 0520 and 0545 UTC on 6 October 1999. To examine the relationship between the wave-scale motions and small-scale mixing, we examined the statistics of the vertical velocity field from $20-\mathrm{Hz}$ sonic anemometer data located at eight levels on the CASES-99 main tower (not shown). Spectral analysis of sonic anemometer data at 30-, 40-, 50-, and 55-m levels indicated that the principal wave period, between 0518 and 0545 UTC, is approximately $100 \mathrm{~s}$. Height-time displays of vertical velocity variance and kurtosis (not shown) indicate transient increases in vertical velocity variance during several distinct times, which suggests the passage of individual billow cores (Palmer et al. 1996). These results are consistent with the direct numerical simulation of Kelvin-Helmholtz billows described by Werne and Fritts (1999).

One question that arises when considering shortlived atmospheric disturbances in the generally quiescent NBL is the influence of those events on atmospheric structure. Some of these influences can be inferred from fluxes calculated from the 60-m tower sonic anemometers. Figure 14 shows 1-min-averaged heat and momentum fluxes from the $55-\mathrm{m}$ level for the period 0500-0600 UTC 6 October 1999. Clearly, all of the fluxes show a marked increase in magnitude during the event period, 0520-0545 UTC, with minimal fluxes both before and after the event. Therefore, the billow event has induced significant mixing at this level and at other levels on the 60-m tower (not shown). Although sonic anemometer measurements
Radial Velocity $(\mathrm{m} / \mathrm{s})$

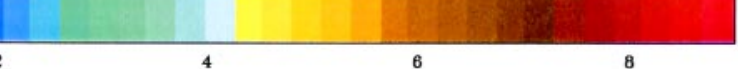

6/1999, Time: $5: 34: 24$ to $5: 34: 55, \mathrm{Az}=10.00$

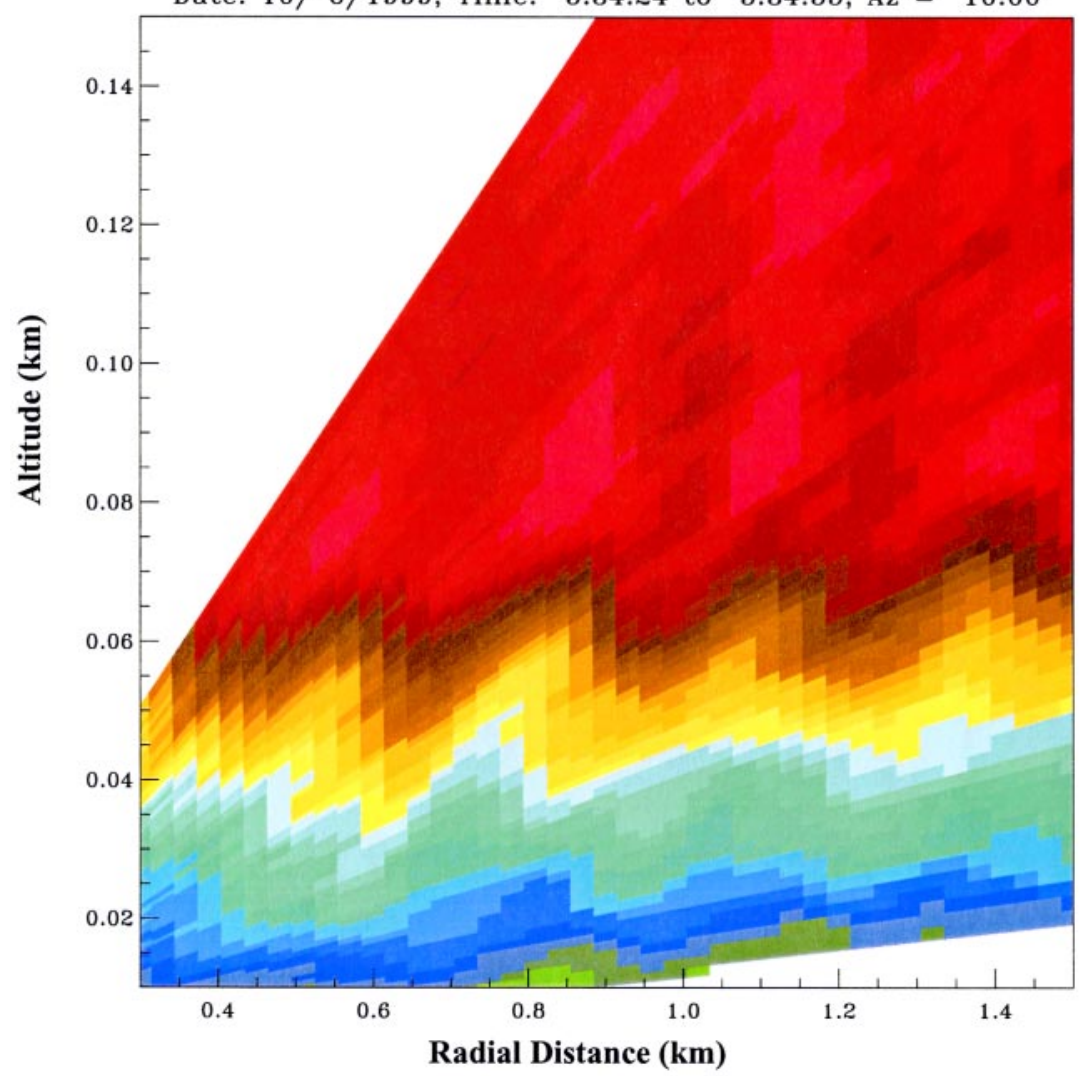

Fig. 13. One representative scan from the NOAA HRDL (lidar) showing a mature stage of the shear instability observed on 6 Oct 1999, IOP-2. by Fig. 13 is highly suggestive of significant mixing well above that level (to the height of the billows). Indeed, these fluxes appear to be significant, even when compared to the strong fluxes during convective daytime conditions, though short-lived. Mixing processes for heat, calculated from the 5 -min heat fluxes, correspond to $\sim 0.6^{\circ} \mathrm{C}$ of cooling across a $10-\mathrm{m}$ layer in $1 \mathrm{~min}$ (0527.5 UTC). Overall, a somewhat smaller cooling rate is distributed across the height of the billow throughout the event period ( $25 \mathrm{~min}$ ). Integrating the heat fluxes in the period from 0520 to $0545 \mathrm{UTC}$ gives an average value of $-0.03^{\circ} \mathrm{C} \mathrm{m} \mathrm{s}^{-1}$ and assuming cooling across the $30-\mathrm{m}$ depth of the event we find an average cooling of $1.5^{\circ} \mathrm{C}$. This upward redistribution of thermal energy cools upper layers and is validated by the $\sim 1.5^{\circ} \mathrm{C}$ cooling during the period shown in Fig. 12a at all tower levels, but most appropriately at the $54.5-\mathrm{m}$ level. Corresponding changes in horizontal wind speed consistent with the indicated fluxes are also evident in Fig. 12b. Thus we find that 


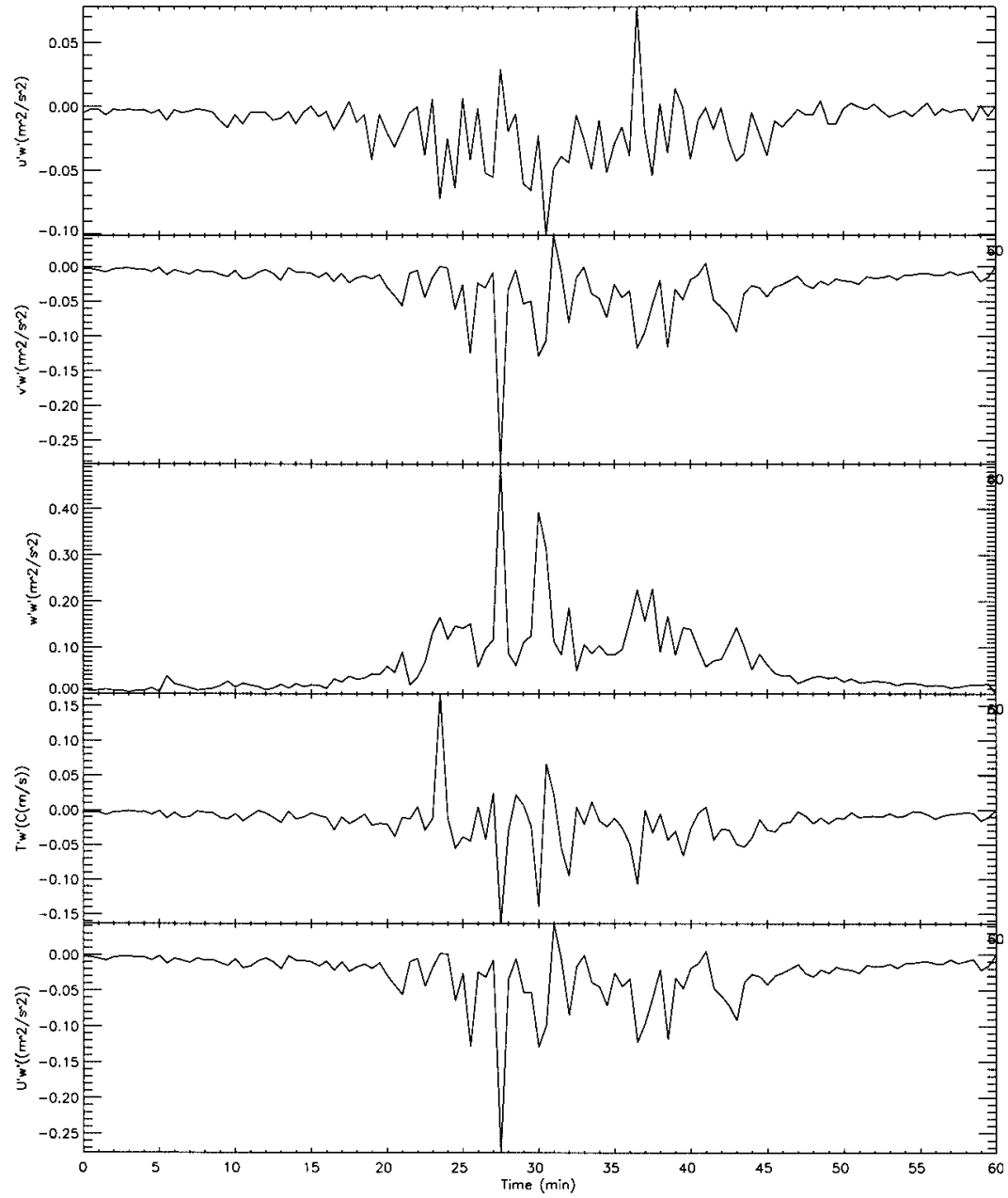

FIG. 14. The I-min-averaged momentum (u' $w^{\prime}, v^{\prime} w^{\prime}, w^{\prime} w^{\prime}$, and $\left.U^{\prime} w^{\prime}\right)$ and heat fluxes $\left(T^{\prime} w^{\prime}\right)$ at $50 \mathrm{~m}$ AGL (with 5-min average removed) from the 60-m tower at the CASES-99 main site. The period shown is 0500-0600 UTC 6 Oct 1999, where the event was primarily confined to 20-45 min past the hour.

this intermittent turbulence inducing phenomenon has caused significant changes in the vertical structure of the NBL.

Further corroborating evidence of the character and influence of this event on the NBL can be extracted from the CASES-99 microbarograph array (see Fig. 3 for locations). In the absence of absolute proof of what this event might be, we can refer to these signatures in the microbarograph measurements as "coherent pressure disturbances." A CPD is any feature in the pressure field that maintains its structure as it moves across the pressure sampling array. Examples include gravity waves, pressure jumps, drainage currents, wind gusts, and eddies.

Figure 15 shows the contours of wavelet energy density in microbars squared per second (e.g., Hauf et al. 1996) for the nighttime period 0100-1300 UTC from one of the six surface-based microbarographs during IOP-2. Intense disturbances occur during the first half of the night, with maximum energy found in eddies with periods near $30 \mathrm{~min}$. Using the beam steering technique in the slowness plane to determine disturbance speed and direction, we find that the billow event in question between 0500 and 0600 UTC, has a phase speed of about $15 \mathrm{~m} \mathrm{~s}^{-1}$, a direction of $124^{\circ}$, and a wavelength of about $14 \mathrm{~km}$. The period of the disturbance is $\sim 15$ min, which corresponds reasonably well with the observed period of the disturbance at upper levels of $25 \mathrm{~min}$. The difference may be attributable to the surface-based location of the microbarogarphs.

Unique microbarograph measurements on the $60-\mathrm{m}$ tower at 1,30 , and $50 \mathrm{~m} \mathrm{AGL}$ also help clarify the nature of this intermittent turbulence event. A wavelet transform has been applied on the recordings, using a Morlet mother wavelet. The integrated WT energy for periods between $2 \mathrm{~s}$ and $3 \mathrm{~min}$ for 0500-0600 UTC (Fig. 16) shows similar structure at the three heights, but with an increase of the associated energy with height. The similarity in WT structure at different heights is evidence of vertical influence on an elevated turbulence event, reinforcing the observation that despite strong static stability, intermittent turbulence events in the NBL can influence atmospheric structure well outside their generation elevation. The recorded signal at $50 \mathrm{~m}$ (not shown) and its integrated WT (Fig. 16) show evidence of oscillatory behavior similar to that in the horizontally distributed microbarographs. The interval of maximum activity observed by the lidar (between 0518 and 0545 UTC) is well captured. The wave phase is almost simultaneous in the recordings at 50 and $30 \mathrm{~m}$ (about 1-s lag), but the lag is $\sim 9$ s larger between 30 - and 1 -m recordings. The maxima of energy density (not shown) from 


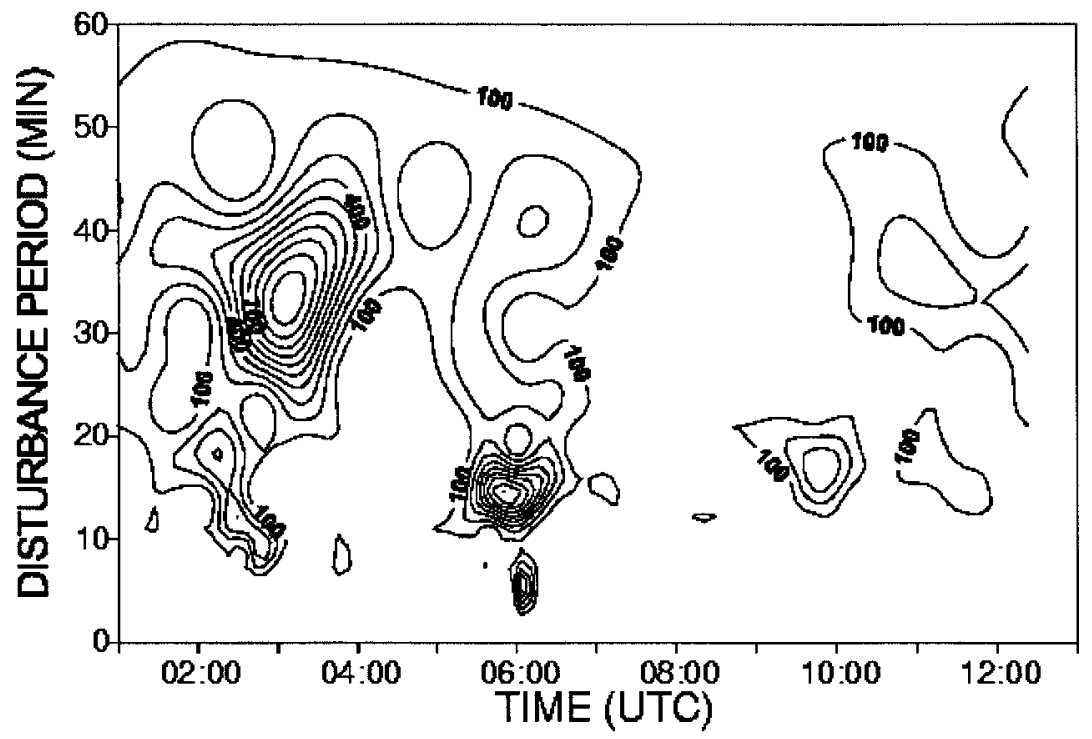

FIG. I5. Contours of wavelet energy density ( $\mu \mathrm{b}^{2} \mathrm{~s}^{-1}$; e.g., Hauf et al. 1996) for the nighttime period 2000-0800 LT (0 1 00-I300 UTC) from one of the six surface-based microbarographs during IOP-2.

0500 to 0600 UTC at the $50-\mathrm{m}$ level have periods of less than 2 min at the times of the peaks in Fig. 16 [0518 (5.3), 0523 (5.4), 0530 (5.5), and 0534 (5.56) UTC], indicating intermittent behavior.

IOP-4, II October 1999, inertial oscillations. As shown in Table 3 (Lundquist 2000), inertial oscillations were frequently observed during the CASES-99 field experiment and are an example of the data that can be utilized to meet our fourth scientific objective. Inertial oscillations (IOs) have a period of about 19 $h$ at the latitude of the CASES99 domain. Typically IOs develop during the evening transition of the boundary layer; later they enhance the evolution of the low-level wind maximum (or jet) that becomes a prominent feature atop the growing nocturnal surface inversion (Buajitti and Blackadar 1957; Blackadar 1957; Thorpe and Guymer 1977; Mahrt 1999). Though other sources have been posited for the development of the low-level jet, including cooling over sloped terrain (Holton 1967) and synoptic-scale pressure gradients (Uccellini 1980; Djuric and Ladwig 1983), a careful modeling study (Zhong et al. 1996) $2 \mathrm{~s}$ and $3 \mathrm{~min}$. concludes that over the Great Plains of the United States, the effect of the IO dominates any effect from baroclinicity due to sloping terrain. Despite their significance to the LLJ, and though they are thought to be ubiquitous in the stable boundary layer, there has not been a quantitative climatology of the presence of IOs in the stable boundary layer. CASES-99 data provides an opportunity for an observation-based verification of their generation during the evening transition.

The five 915-MHz boundary layer profilers located at Beaumont, Whitewater, Oxford, Smileyburg, and El Dorado, Kansas (Fig. 2), provide hourly averages of winds from approximately 150-2000 m sufficient for IO analysis. The regular soundings at the main Leon site and the auxiliary Beaumont, El Dorado, and Smileyburg sites provide thermodynamic profiles of the NBL. Each time series of wind speed and wind direction from one profiler level over one night is presumed to consist of a mean wind, an inertially oscillating component, and noise. To determine the significance of an extracted IO, the amplitude of the IO is compared to the noise component of the wind speed:

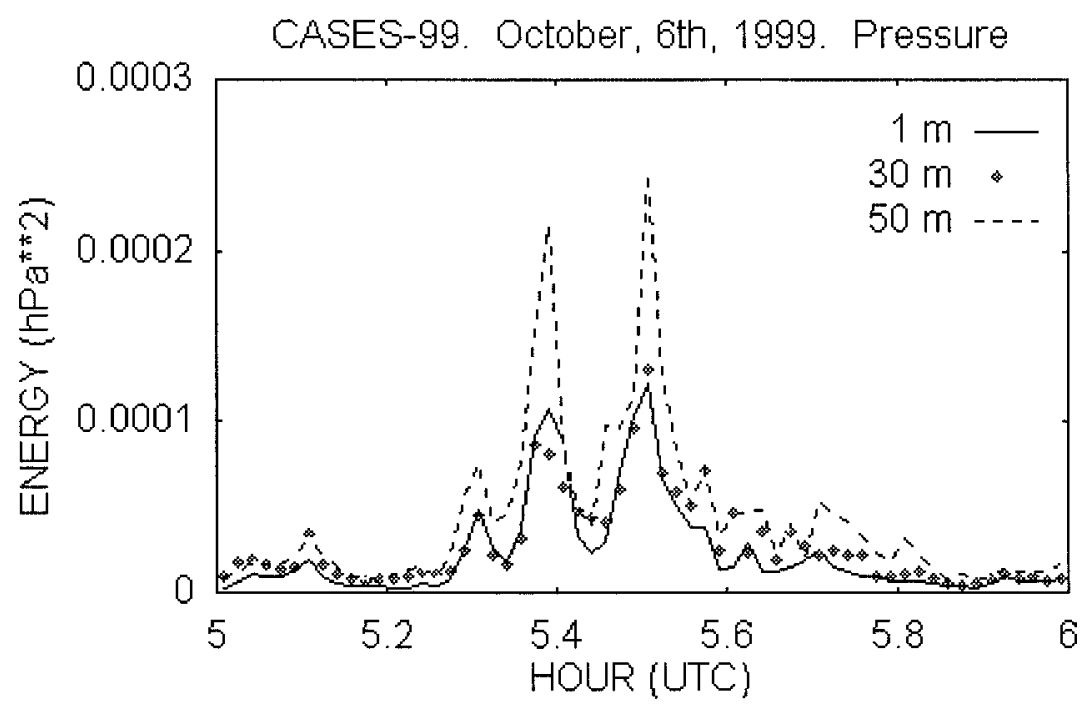

FIG. 16. Temporal evolution of the wavelet transform energy for the three microbarographs ( $I, 30$, and $50 \mathrm{~m}$ AGL) integrated for periods between 


$$
R_{\mathrm{ws}}=\frac{\mid \text { noise } \mid}{A_{\mathrm{IO}}},
$$

where $A_{\mathrm{IO}}$ is the calculated amplitude of the IO and |noise| is the average value of the wind speed remaining after the mean wind and the IO are removed from the time series. Based on a review of hundreds of calculations of $R_{\mathrm{ws}}$, it has been empirically determined that when $R_{\mathrm{ws}} \leq 0.5$, the IO should be considered significant. As a second check, the probability density functions (PDFs) of the wind direction of the noise
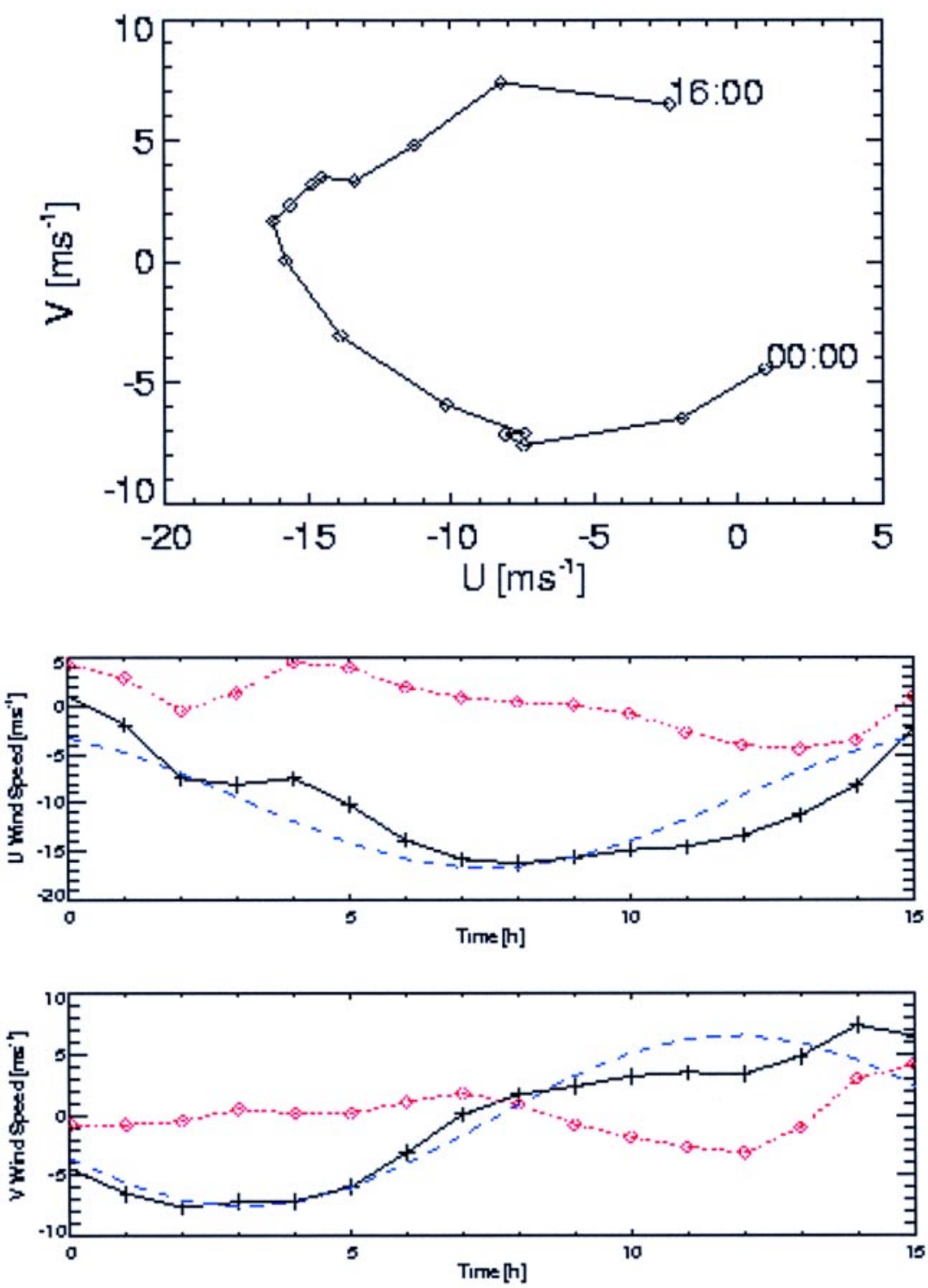

Fig. 17. (top) The hodograph of the winds observed from 0000 to 1600 UTC at EI Dorado at $36 \mathrm{I} \mathrm{m}$ during IOP-4. (middle and bottom) Time series of the zonal and meridional winds. The solid line represents the observed data; the dashed line is the "best-fit" 10; the dotted line is the noise remaining after the mean winds and the 10 have been removed from the time series. component have been inspected to ensure that they are Gaussian. Figure 17 depicts one time series that fulfills the criteria to be considered an IO. For additional details on the IO extraction, see Lundquist (2000).

This technique has been applied to the data from the lowest $2 \mathrm{~km}$ of the 5 CASES-99 915-MHz boundary layer wind profilers from 3 to 29 October. Of the 27 evenings examined, 9 nights show evidence of IOs commencing at 0000 UTC (see Table 3), 1-2 h after the surface heat flux changes sign, and lasting for 14$16 \mathrm{~h}$ at two or more profiler sites. Winds below $150 \mathrm{~m}$ are not available from boundary layer profilers, and are often not available from GPS soundings, so it is not possible to determine if IOs are present at or below the inversion level on these nights.

One of these nights can illustrate the role of IOs in the development of the jet profile in the winds of the stable boundary layer. The day of 10 October, prior to IOP-4, is marked by moderate winds, warm temperatures, few clouds, and the growth of a convective boundary layer. The mixed layer, sampled by a sounding at the main Leon site, grows to $1400 \mathrm{~m}$ by 2300 UTC on 10 October (see Fig. 18). The ELD profiler indicates that winds are $4-5 \mathrm{~m} \mathrm{~s}^{-1}$ from the north. Based on tower measurements the surface heat flux changes sign at 2230 UTC. By 0100 UTC on 11 October, the wind profiles confirm LLJ development (Fig. 19). The 0300 UTC sounding and profiler data show a distinct jet structure in the wind. This jet persists through the night, with the wind direction rotating through the east as the wind speeds in the jet increase to $18 \mathrm{~m} \mathrm{~s}^{-1}$ by 0700 UTC. The speed in the jet maximum remains constant through 1200 UTC, and then starts to diminish. Throughout the night, all jet development is confined to below $600 \mathrm{~m}$; profiler resolution does not reveal whether the 
jet max rises or lowers over the course of the night. Thermodynamic data from the radiosonde at midnight local (0700 UTC) reveals that atop a sharp surface inversion ( 4 K over $150 \mathrm{~m}$ ), a statically stable layer (7 K over $\sim 450 \mathrm{~m}$ ) exists from 150 to $600 \mathrm{~m}$. Above $600 \mathrm{~m}$, the residual mixed layer survives the entire night (Fig. 18).

Analysis of the IOs on this night shows that IOs occur primarily in the very stable layer below $600 \mathrm{~m}$ and generate a large component of the LLJ vector. The inertially oscillating component of the wind, which commences its oscillation at 0000 UTC, has an initial wind direction of approximately $290^{\circ}$. The IO and mean wind component line up at 0700 UTC, the same time that the jet reaches its maximum. On this night, inertial oscillations in the stable layer enhance the development of the maximum in wind speed in the lower levels of the boundary layer by $30 \%$ through the vertical extent of the jet, although a weaker jet profile would still be evident without the influence of the IO.

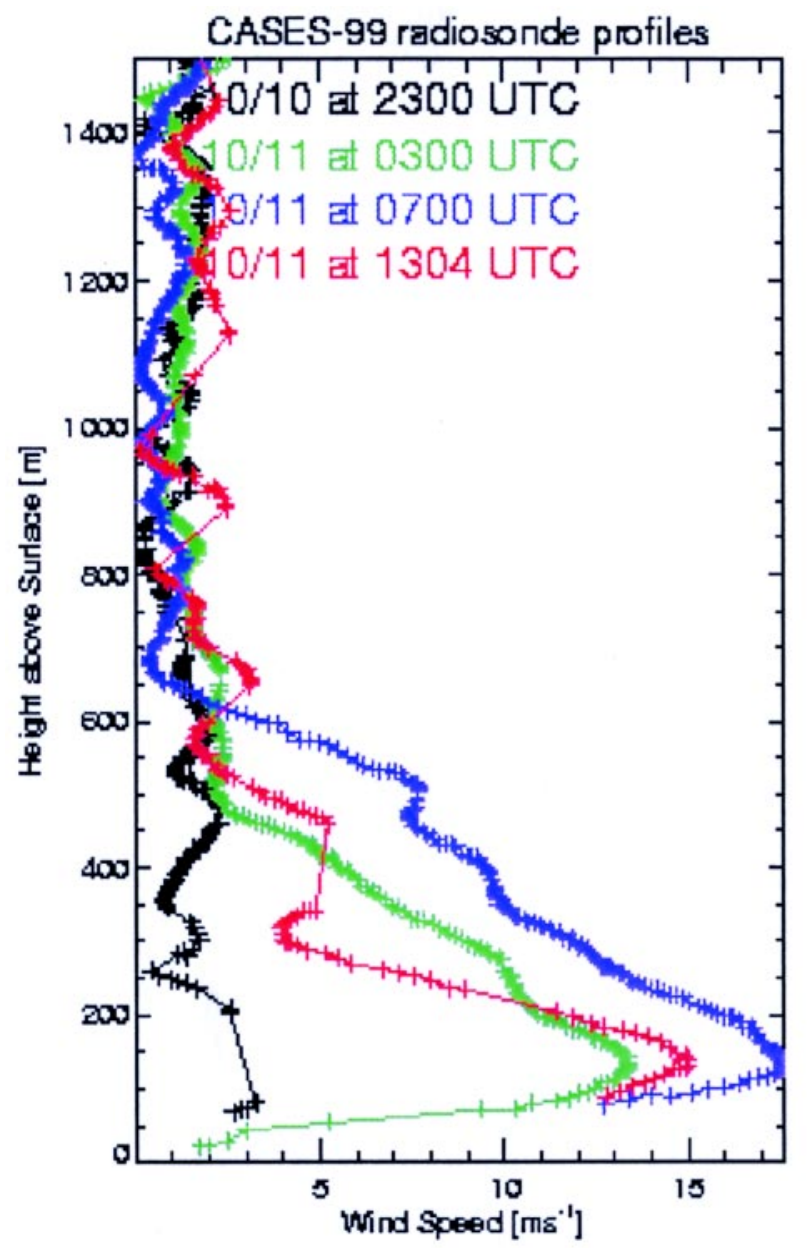

SUMMARY. CASES-99 is an investigation of the NBL and its transitions, whose primary focus is on data analysis from a field experiment held during October 1999. A broad range of instruments were utilized, including many useful remote sensing instruments, aircraft, surface-based, and elevated high-frequency sensors in overnight sampling for 11 IOPs. The data from these IOPs are shown, here in preliminary form, to begin to address portions of each of the four scientific goals. These goals are, in short, (see introduction for more detail) the following: 1) to provide a time history of NBL phenomena, and to evaluate their contributions to intermittent heat, moisture, and momentum fluxes; 2) to measure fluxes and their divergences throughout the nocturnal boundary layer and surface layer to assess the departures from similarity theory under otherwise dynamically stable conditions; 3 ) to define the relative importance of surface heterogeneity on NBL evolution; and 4) to compare measurements with existing models of

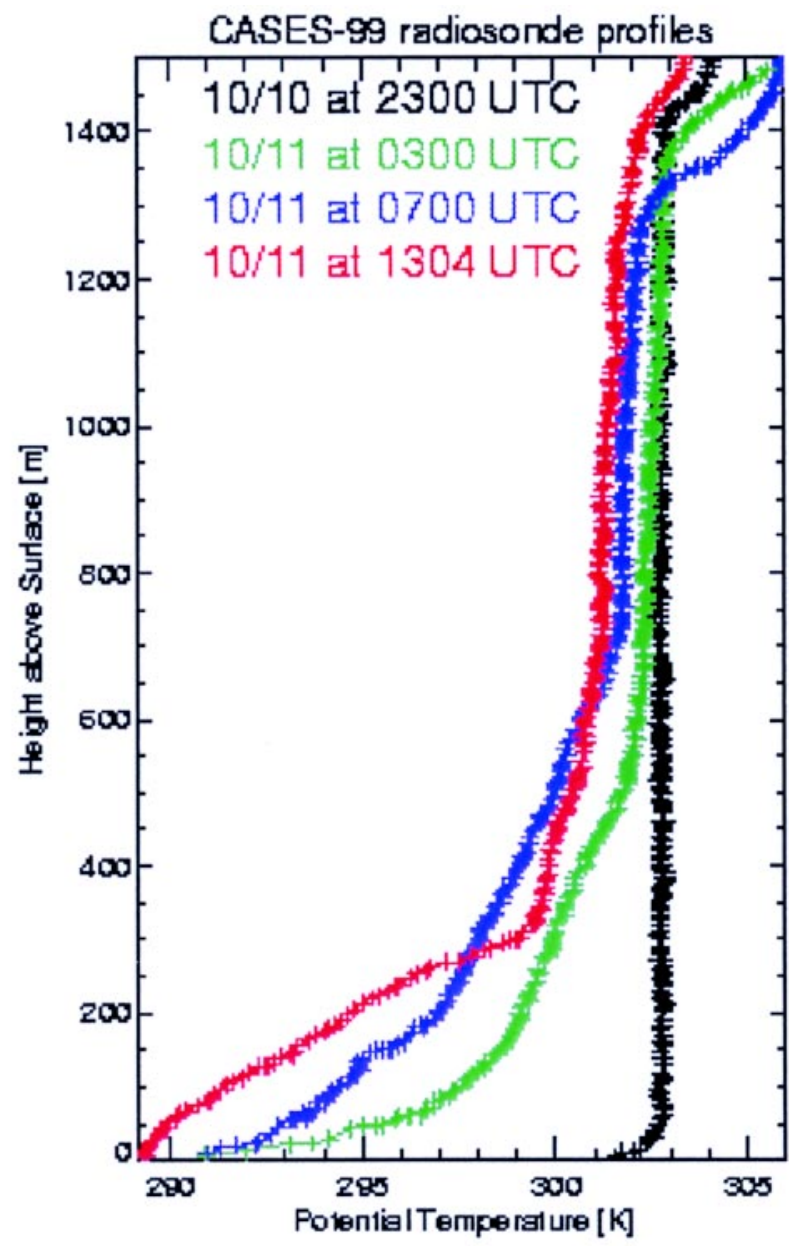

FIG. I 8. Profiles of (left) wind speed and (right) potential temperature from radiosonde data on the night of I0I I Oct 1999, IOP-4. The + symbol indicates actual observations; some gaps exist in the winds portion of the dataset. 


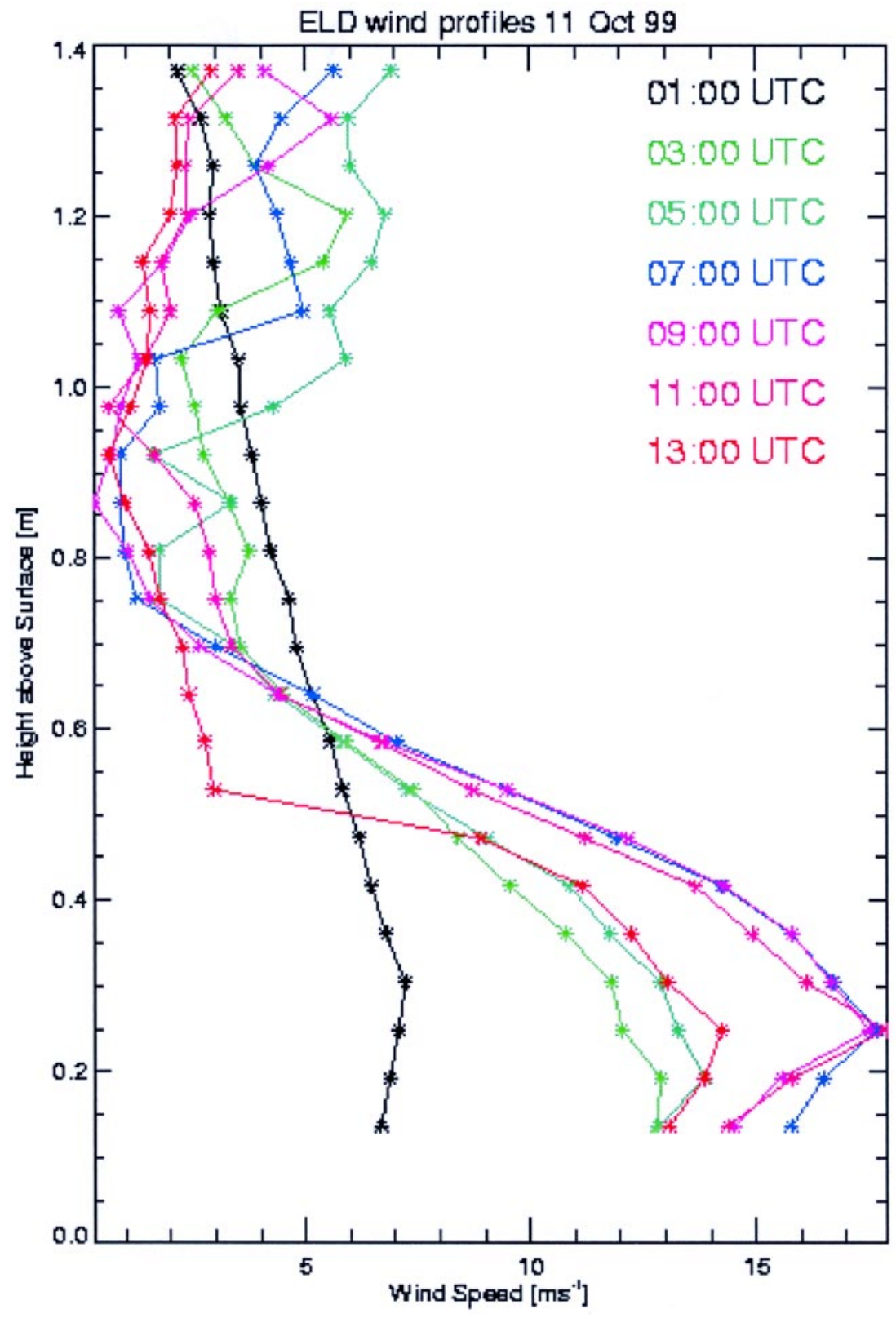

FIG. 19. Wind profiler data from El Dorado through the night of I0-I I Oct 1999, IOP-4, during which an inertial oscillation pattern was observed.

provide deviations from a dynamically stable condition. In Kansas, these phenomena are frequently generated from the upper levels of the NBL and have influence downward due to nocturnal jets that form with influence from inertial oscillations. These jets are not confined to a particular orientation, such as the Great Plains lowlevel jet (e.g., Zhong et al. 1996), which is generally considered to be a southerly phenomenon, with a jet maximum at altitudes $100 \mathrm{~m}$ or more above the jet maxima observed during CASES-99. The fluxes generated from one event are shown to have a significant effect on the vertical structure of the NBL despite its short-lived existence ( $25 \mathrm{~min})$. While not conclusive given the small sampling presented herein, typical horizontal, vertical, and timescales for intermittent phenomena observed at CASES-99 are $O(10-100) \mathrm{m}$, $O(1-10) \mathrm{m}$, and $O(100-1000) \mathrm{s}$, respectively. The challenge, in part, lies in adequately representing the influence of these microscale phenomena within numerical models that typically use larger-scale grid spacing.

Ongoing efforts investigating the wide variety of events sampled during the CASES-99 field experiment are yielding additional information on their sources and characteristics, such

the transition periods, and to asses the role of the transition period in the initiation of inertial oscillations and the enhancement of low-level jets. Overall, it is anticipated that addressing these scientific goals will provide a basis for the improvement of the representation of surface layer fluxes, and also near-surface turbulence fluxes, within numerical models of the atmosphere.

Information provided herein shows that what at the surface may appear, due to weak winds and strong static stability, to be a relatively quiescent nocturnal boundary layer, may in fact be intermittently populated with a variety of atmospheric phenomena that that a robust understanding of the NBL can be achieved. Further, many modeling techniques and theoretical tactics are being applied within CASES-99 to improve model performance during conditions where intermittent turbulence predominates.

We encourage all interested parties to pursue investigations utilizing the CASES-99 data archive that is freely available online at www.joss.ucar.edu/cases99/.

ACKNOWLEDGMENTS. We would like to acknowledge the following people for their significant role the success of CASES-99 experiment: Jerry Klazura of Argonne 
National Laboratory, who was instrumental in the logistics of the setup and operation of the COT, contacting landowners, and keeping the local community informed; Holly Hayes of Colorado Research Associates, a division of NWRA, in helping to organize the Operational Plan; Steve Oncley, Carolyn Simerly, and colleagues at NCAR ATD for their fine support, administration, and deployment of the Lower Atmospheric Observing Facility, and especially the heavily instrumented 60-m tower; and Rich Coulter and Jerry Klazura for the ABLE wind profiler data. On the whole, the active participation in planning and cooperative efforts at bringing a wide variety of relevant instruments to the field by the CASES-99 participants should be pointed to as the primary means for our success.

Financial support is provided, in part, for WB by the U.S. Army Research Office, and for WB and JKL by the National Science Foundation, Mesoscale Dynamics Program. Both are gratefully acknowledged. Dave Fritts acknowledges the support of NSF Grant ATM-9908615. Greg Poulos acknowledges the overall support of the Grants ARO DAAD19-99C-0037, NSF ATM-0002093, and, for data analysis, DOE DE-FG03-99ER62839. This work was supported by the U.S. Department of Energy under the auspices of the Environmental Meteorology Program of the Office of Biological and Environmental Research. Carmen Nappo acknowledges the support of the U.S. Army Research Laboratory under Grant MIPROB-NOAA007. JS and SB acknowledge the support of Army Research Office Grant DAAD 19991-0320, National Science Foundation Grant ATM-9906637, and Xuhui Lee and Xin-Zhang $\mathrm{Hu}$ at Yale University for their help with the thermocouples. BB and MJ, who run the tethered lifting system, would like to acknowledge the NSF under Grant ATM 9907289 and the FAA for providing the necessary clearances for flying the TLS platforms under nighttime conditions in a relatively congested area. JC and ET acknowledge the Spanish Commission for Science and Technology through Projects CLI97-0343 and CLI99-1326E. We gratefully acknowledge the many landowners who allowed CASES-99 investigators to deploy instruments.

\section{APPENDIX: LIST OF ACRONYMS.}

ABLE

AGL

ANL

APO

ARM-CART

ARO

ATD

ATDD
Argonne Boundary Layer Experiment

Above ground level

Argonne National Laboratory

Argonne Project Office

Atmospheric Radiation MeasurementClouds and Radiation Testbed

Army Research Office

Atmospheric Technology Division

(NCAR)

Atmospheric Turbulence and

Diffusion Division
CASES

CBL

CoRA

COT

$\mathrm{CPD}$

CSU

DNS

DOE

ETL

FM-CW

GLASS

GPS

HRDL

INEL

INM

IO

IOP

ISS

ISFF

JOSS

$\mathrm{KH}$

LANL

LES

LIDAR

LLJ

NBL

NCAR

NOAA

NSF

NWS

OSU

PBL

RADAR

RAMS

RASS

SGS

SBL

SODAR

TEP

TLS

UCAR

VAD

WRW

WT
Cooperative Atmosphere-Surface

Exchange Study

Convective boundary layer

Colorado Research Associates

CASES-99 operations trailer

Coherent pressure disturbance

Colorado State University

Direct numerical simulation

Department of Energy

Environmental Technology

Laboratory (NOAA)

Frequency modulation-continuous wave

GPS/Loran atmospheric sounding system

Global positioning system

High-resolution Doppler lidar

Idaho National Energy Laboratory

Instituto Nacional de Meteorologia

Inertial oscillation

Intensive observation period

Integrated Sounding System

Integrated Surface Flux Facility

Joint Office for Science Support

(UCAR)

Kelvin-Helmholtz

Los Alamos National Laboratory

Large eddy simulation

Light detection and ranging

Low-level jet

Nocturnal boundary layer

National Center for Atmospheric

Research

National Oceanographic and Atmospheric Administration

National Science Foundation

National Weather Service (NOAA)

Oregon State University

Planetary boundary layer

Radio detection and ranging

Regional Atmospheric Modeling

System

Radio acoustic sounding system

Subgrid scale

Stable boundary layer

Sound detection and ranging

Turbulent eddy profiler

Tethered Lifting System

University Corporation for Atmo-

spheric Research

Velocity-azimuth display

Walnut River watershed

Wavelet transform 
REFERENCES

Balsley, B. B., J. B. Williams, G. W. Tyrrell, and C. L. Balsley, 1992: Atmospheric research using kites: Here we go again! Bull. Amer. Meteor. Soc., 73, 179.

—_, J. W. Birks, M. L. Jensen, K. G. Knapp, J. B. Williams, and G. W. Tyrrell, 1994: Ozone profiling using kites. Nature, 369, 23-29.

Banta, R. M., and P. T. Gannon Sr., 1995: Influence of soil moisture on simulations of katabatic flow. Theor. Appl. Climatol., 52, 85-94.

Baujitti, K., and A. Blackadar, 1957: Theoretical studies of diurnal wind-structure variations in the planetary boundary layer. Quart. J. Roy. Meteor. Soc., 83, 486500 .

Blackadar, A. K., 1957: Boundary layer wind maximum and their significance for the growth of nocturnal inversions. Bull. Amer. Meteor Soc., 38, 283-290.

Blumen, W., R. L. Grossman, and M. Piper, 1999: Analysis of heat flux, dissipation and frontogenesis in a shallow density current. Bound.-Layer Meteor., 91, 281-306.

—-, R. Banta, S. P. Burns, D. C. Fritts, R. Newsom, G. S. Poulos, and J. Sun, 2001: Turbulent statistics of a Kelvin-Helmholtz billow event observed in the nighttime boundary layer during the CASES-99 field program. Dyn. Atmos. Oceans, 34, 189-204.

Caughey, S. J., and C. J. Readings, 1975: An observation of waves and turbulence in the Earth's boundary layer. Bound.-Layer Meteor., 9, 279-296.

Chen, F., Z. Janjic, and K. Mitchell, 1997: Impact of atmospheric surface-layer parameterization in the new land-surface scheme of the NCEP mesoscale Eta Model. Bound.-Layer Meteor., 85, 391-421.

Cheney, N. R., and J. A. Businger, 1990: An acurate fast response temperature system using thermocouples. J. Atmos. Oceanic Technol., 7, 504-516.

Denholm-Price, J. C. W., and J. M. Rees, 1999: Detecting waves using an array of sensors. Mon. Wea. Rev., 127, 57-69.

Derbyshire, S. H., 1995: Stable boundary layers: Observations, models and variability. Part I: Modeling and measurements. Bound.-Layer Meteor., 74, 19-54.

__, 1999: Boundary-layer decoupling over cold surfaces as a physical boundary instability. Bound.-Layer Meteor., 90, 297-325.

De Silva, L. P. D., H. J. S. Fernando, F. Eaton, and D. Hebert, 1996: Evolution of Kelvin-Helmholtz billows in nature and laboratory. Earth Planet. Sci. Lett., 143, 217-231.

Djuric, D., and D. S. Ladwig, 1983: Southerly low-level jet in the winter cyclones of the southwestern Great Plains. Mon. Wea. Rev., 111, 2275-2281.
Elliott, W. P., 1964: The height variation of vertical heat flux near the ground. Quart. J. Roy. Meteor. Soc., 90, 260-265.

Fernando, H. J. S., 1991: Turbulent mixing in stratified fluids. Annu. Rev. Fluid Mech., 23, 455-493.

Finnigan, J. J., F. Einaudi, and D. Fua, 1984: The interaction between an integral gravity wave and turbulence in the stably-stratified nocturnal boundary layer. J. Atmos. Sci., 41, 2409-2436.

Funk, J. P., 1960: Measured radiative flux divergence near the ground at night. Quart. J. Roy. Meteor. Soc., 86, 382-389.

Gopalakdrishnan, S. G., M. Sharan, R. T. McNider, and M. P. Singh, 1998: Study of radiative and turbulent processes in the stable boundary layer under weak wind conditions. J. Atmos. Sci., 55, 954-960.

Grund, C. J., R. M. Banta, J. L. George, J. N. Howell, M. J. Post, R. A. Richter, and A. M. Weickmann, 2001: Highresolution Doppler lidar for boundary layer and cloud research. J. Atmos. Oceanic Technol., 18, 376-393.

Gryning, S.-E., 1985: The oresund experiment-A Nordic mesoscale dispersion experiment over a land-water-land area. Bull. Amer. Meteor. Soc., 66, 1403-1407.

Hartel, C., and L. Kleiser, 1998: Analysis and modeling of subgrid-scale motions in near-wall turbulence. $J$. Fluid Mech., 356, 327-352.

Hauf, T., U. Finke, J. Neisser, G. Bull, and J.-G. Strangenberg, 1996: A ground-based network for atmospheric pressure fluctuations. J. Atmos. Oceanic Technol., 53, 1001-1023.

Hill, R. J., 1997: Applicability of Kolmogorov's and Monin's equations of turbulence. J. Fluid Mech., 353, $67-81$.

Holton, J. R., 1967: The diurnal boundary layer wind oscillation above sloping terrain. Tellus, 19, 199-205.

Horst, T. W., and J. C. Doran, 1986: Nocturnal drainage flow on simple slopes. Bound.-Layer Meteor., 3, 263-286.

Howard, L. N., 1961: Note on a paper by John Miles. J. Fluid Mech., 10, 509-512.

Howell, J., and L. Mahrt, 1997: Multiresolution flux decomposition. Bound.-Layer Meteor., 83, 117-137.

_- , and J. Sun, 1997: Surface layer fluxes in stable conditions. Bound.-Layer Meteor., 90, 495-520.

Kunkel, K. E., and D. L. Walters, 1982: Intermittent turbulence in measurements of the temperature structure parameter under very stable conditions. Bound.Layer Meteor., 22, 49-60.

LeMone, M., and Coauthors, 2000: Land-atmosphere interaction research, early results and opportunities in the Walnut River Watershed in southeast Kansas: CASES and ABLE. Bull. Amer. Meteor. Soc., 81, 757779. 
Lenschow, D. H., X. S. Li, C. J. Zhu, and B. B. Stankov, 1998a: The stably stratified boundary layer over the Great Plains. Part I: Mean and turbulence structure. Bound.-Layer Meteor., 42, 95-121.

— , S. F. Zhang, and B. B. Stankov, 1988b: The stably stratified boundary layer over the Great Plains. Part II: Horizontal variations and spectra. Bound.-Layer Meteor., 42, 123-135.

Louis, J. F., 1979: A parametric model of vertical eddy fluxes in the atmosphere. Bound.-Layer Meteor., 17, 187-202.

Lundquist, J. K., 2000: Inertial oscillations and boundary-layer dynamics: The evening transition of the atmospheric boundary layer. Ph.D. dissertation, University of Colorado, $130 \mathrm{pp}$. [Available from the Program in Atmospheric and Oceanic Sciences, University of Colorado, Boulder, CO 80302.]

Mahrt, L., 1998: Stratified atmospheric boundary layers and breakdown of models. J. Theor. Comput. Fluid Dyn., 11, 263-280.

_-, 1999: Stratified atmospheric boundary layer. Bound.-Layer Meteor., 90, 375-396.

- J. J. Sun, W. Blumen, T. Delany, and S. Oncley, 1997: Nocturnal boundary-layer regimes. Bound.-Layer Meteor., 88, 255-278.

McNider, R. T., D. E. England, M. J. Friedman, and X. Shi, 1995: Predictability of the stable atmospheric boundary layer. J. Atmos. Sci., 52, 1602-1623.

Miles, J. W., and L. N. Howard, 1964: Note on heterogeneous shear flow. J. Fluid Mech., 20, 331-336.

Muschinski, A., and C. Wode, 1998: First in situ evidence of coexisting submeter temperature and humidity sheets in the lower free troposphere. J. Atmos. Sci., 55, 2893-2906.

Nappo, C., 1991: Sporadic breakdowns of stability in the PBL over simple and complex terrain. Bound.-Layer Meteor., 54, 69-87.

— - and P.-E. Johansson, 1998: Summary report of the Lovanger international workshop on turbulence and diffusion in the stable planetary boundary layer. Bull. Amer. Meteor. Soc., 79, 1401-1405.

Nkemdirim, L. C., 1978: A comparison of radiative and actual nocturnal cooling rates over grass and snow. J. Appl. Meteor., 17, 1643-1646.

Palmer, T. L., D. C. Fritts, and O. Andreassen, 1996: Evolution and breakdown of Kelvin-Helmholtz billows in stratified compressible flows. Part II: Instability, structure, evolution, and energetics. J. Atmos. Sci., 53, 3192-3212.
Pielke, R. A., and Coauthors, 1992: A comprehensive meteorological modeling system-RAMS. Meteor. Atmos. Phys., 49, 69-91.

Poulos, G. S., 1996: The interaction of katabatic winds and mountain waves. Ph.D. dissertation, Colorado State University, Fort Collins, CO, 300 pp. [Available from the Department of Atmospheric Science, Colorado State University, Fort Collins, CO 80523.]

- - and J. E. Bossert, 1995: An observational and prognostic numerical investigation of complex terrain dispersion. J. Appl. Meteor., 34, 650-669.

Revelle, D. O., 1993: Chaos and "bursting" in the planetary boundary layer. J. Appl. Meteor., 32, 11691180.

Rider, N. E., and G. D. Robinson, 1951: A study of the transfer of heat and water vapor. Quart. J. Roy. Meteor. Soc., 77, 375-401.

Saiki, E. M., C.-H. Moeng, and P. P. Sullivan, 2000: Large eddy simulation of the stably stratified planetary boundary layer. Bound.-Layer Meteor., 95, 1-30.

Scorer, R. S., 1997: Dynamics of Meteorology and Climate. John Wiley \& Sons, 686 pp.

Sun, J., and Coauthors, 2002: Intermittent turbulence associated with a density current passage in the stable boundary layer. Bound.-Layer Meteor., in press.

Thorpe, A. J., and T. H. Guymer, 1977: The nocturnal jet. Quart. J. Roy. Meteor. Soc., 103, 633-653.

Thorpe, S. A., 1973: Experiments on instability and turbulence in stratified shear flow. J. Fluid Mech., 61, 731-751.

Uccellini, L. W., 1980: On the role of upper tropospheric jet streaks and leeside cyclogenesis in the development of low-level jets in the Great Plains. Mon. Wea. Rev., 108, 1689-1696.

Weber, A. H., and R. J. Kurzeja, 1991: Nocturnal planetary boundary layer structure and turbulence episodes during the Project STABLE field program. J. Appl. Meteor., 30, 1117-1133.

Werne, J., and D. C. Fritts, 1999: Stratified shear turbulence: Evolution and statistics. Geophys. Res. Lett., 26, 439-442.

- , and —, 2001: Anisotropy in a stratified shear layer. Phys. Chem. Earth, 26B, 263-268.

Zhong, S., J. D. Fast, and X. Bian, 1996: A case study of the Great Plains low-level jet using wind profiler network data and a high-resolution mesoscale model. Mon. Wea. Rev., 124, 785-806. 